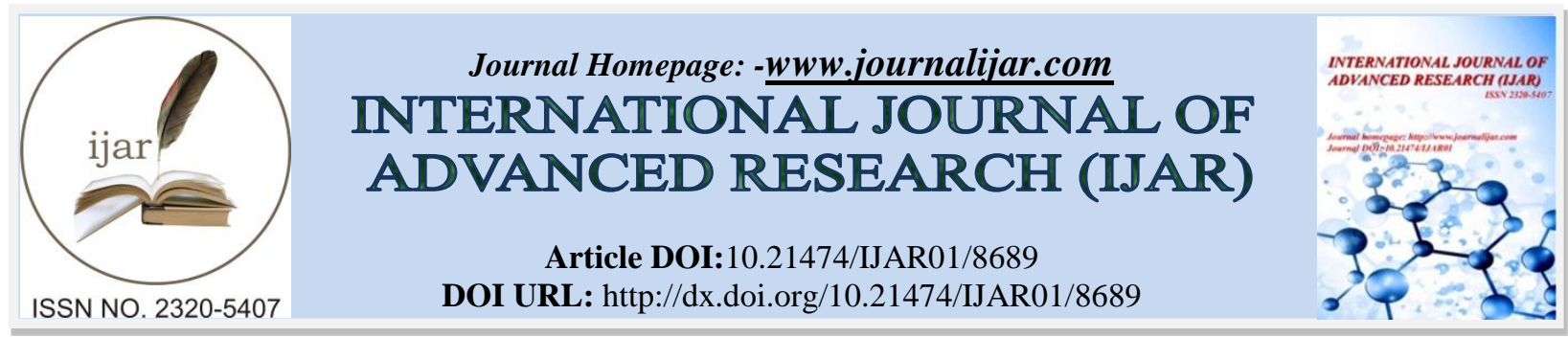

RESEARCH ARTICLE

\title{
AN IN-VITRO EVALUATION AND COMPARISON OF THE FRACTURE RESISTANCE OF TEETH PREPARED BY SELF ADJUSTING FILE, AND OBTURATED WITH THREE DIFFERENT OBTURATION TECHNIQUES.
}

\author{
Dr. Pratishtha Tanwar.
}

\section{Manuscript Info}

Abstract

Manuscript History

Received: 13 January 2019

Final Accepted: 15 February 2019

Published: March 2019

Copy Right, IJAR, 2019,. All rights reserved.

\section{Introduction:-}

Endodontically treated teeth are widely considered to be more susceptible to fracture then the vital teeth. The reasons most often reported have been the dehydration of dentin after endodontic therapy, excessive pressure during obturation and the removal of tooth structure during endodontic treatment.

Studies have shown that as removal of tooth structure increases, fracture resistance decreases. Root canal instrumentation is an unavoidable step in endodontic treatment. However, it is understood that as dentin is removed during instrumentation phase, a weakening effect on the root is occurred ${ }^{1}$.

There is a concept that root canal treatment weakens tooth structure and predisposes teeth to fracture. Excessive instrumentation is shown to enhance this weakening effect. It has been reported that the incidence of vertical root fractures is greater in root filled teeth. ${ }^{2}$ The reason includes the loss of moisture in dentin resulting in brittleness of root filled teeth after the endodontic procedures. This hypothesis was put forward by G.V.Black, and later given credence by Helfer et al who reported that the moisture content of dentin from endodontically treated teeth was about $9 \%$ less than teeth with vital pulp ${ }^{3}$.

The most susceptible roots to fracture are those with a narrow mesiodistal diameter compared with the buccolingual dimension as in maxillary premolars, mesial roots of mandibular molars, and mandibular incisors. Most commonly, VRF occur in endodontically treated teeth. Hence, some endodontic procedures, such as preparation techniques that over enlarge the canal and aggressive nickel-titanium (NiTi) instruments with large tapers have been identified as etiologic factors. During preparation, the contact between instrument and canal walls creates momentary stress concentrations in dentin. Those may leave dentinal defects in which VRF can initiate. It has been suggested that more dentinal defects may be produced by a higher number of rotations and that instrument design variations alter the forces on a root during instrumentation and increase those defects ${ }^{4}$.

Recently, a new file system (self adjusting file) was introduced into the NiTi instrument family with totally new design. SAF is a hollow file designed as a compressible, thin-walled, pointed cylinder composed of a thin NiTi lattice. The file is designed to be compressed while inserted into narrow root canal; it attempts to regain its original dimension, thus applying a constant delicate pressure on the canal walls. 
SAF uses a minimally invasive approach, removing only a thin uniform layer of dentin from the entire perimeter of the canal. SAF is safer in terms of maintaining dentin integrity. The SAF file touches the inner canal wall in all points as a result of compressible and expansive structure of lattice. This characteristic might not create any microcrack in dentine because of the inhibition of stress formation along the root canal. Whereas, rotary files may reduce the thickness of the remaining dentine on the inner side of the curvature to such an extent that it increases the risk of vertical root fracture ${ }^{5}$.

Root fracture is also associated with obturation techniques, some studies have also suggested that lateral condensation creates stresses in the root during obturation, which could lead to subsequent fracture, although lateral condensation should not be a direct cause of vertical root fracture. It may be because dentin has sufficient elasticity to permit separation without complete vertical root fracture ${ }^{6}$.

Spreader design and applied forces are suggested as the contributing factors to the appearance of vertical root fracture during lateral compaction. Now, several techniques where no compaction forces are used have been proposed like passive obturation techniques which produce apical seal similar to lateral compaction.

The potential for VRF is also present with warm vertical compaction as the forces used may be equal to the forces of lateral compaction. According to some studies, lateral compaction of gutta percha results in significantly more dentinal defects than gutta percha obturated with a passive technique or the microcracks formations are more in teeth obturated with lateral condensation then other techniques in which forces are not applied to condense the gutta percha ${ }^{7}$.

Hence, the purpose of this study is to evaluate and compare the impact of various obturation techniques, on the fracture resistance of teeth prepared with Self Adjusting File system.

\section{Aim And Objectives:-}

AIM- To evaluate and compare the fracture resistance of teeth which are prepared by Self Adjusting File (SAF) and filled with three different obturation techniques, i.e. warm vertical compaction technique, cold lateral compaction technique and thermafil obturation technique.

\section{Objectives Of The Study:-}

To evaluate the fracture resistance of:

1. Teeth which are prepared by SAF but not filled

2. Teeth which are prepared by SAF, and obturated with warm vertical compaction technique.

3. Teeth which are prepared by SAF, and obturated with cold lateral compaction technique.

4. Teeth which are prepared by SAF, and obturated with thermafil obturation technique.

5. To compare the fracture resistance of all the groups.

\section{Materials And Method:- \\ Armamentarium included ${ }^{\text {fig } 2}$ : \\ Instruments:}

1. Diamond Disc (FNS,Germany)

2. Micromotor- Straight Hand Piece (NSK, Japan)

3. K file \#10 (Dentsply; Maillefer)

4. Endomotor-XSmart (Dentsply)

5. Endodontic Rotary files- VDW GmbH

6. Lentulo- Spiral (Dentsply Maillefer)

7. Caliper

8. Copper Ring Mould

9. Finger Spreader (Dentsply Maillefer)

10. Endodontic Pluggers (Sybron Endo)

11. Self Adjusting File System ( ReDent- Nova, Israel)

12. Thermafil Obturation System (Dentsply Maillefer)

13. Obtura System (Kerr Dental) 


\section{Materials:-}

1. Mouth Mask

2. Hand Gloves

3. Storage Medium- 10\% Buffered Formalin

4. $3 \%$ Sodium Hypochlorite ( Chemident, India)

5. $17 \%$ EDTA (Ultradent, India)

6. $5 \mathrm{ml}$ Syringe (Medic, India)

7. Paper Point (Meta Biomed, India)

8. Endodontic Sealer- AH Plus (Dentsply, Germany)

9. Gutta Percha Cones (Dentsply)

10. Cavit $^{\mathrm{TM}} \mathrm{G}$ (3M ESPE)

11. Acrylic Resin

12. Extra Light Body Impression Material (Precision VPS DenMat)

13. Base Plate Wax

14. Normal Saline

\section{Equipments:}

Incubator (Bionics Scientific, India)

Universal Testing Machine (Star Testing System, India)

Stereomicroscope (Olympus, Japan)

\section{Method of sample collection:}

80 freshly extracted mandibular premolars, extracted because of orthodontic reasons.

\section{Criteria for sample selection:}

\section{Inclusion criteria:}

Freshly extracted human single rooted mandibular premolars, extracted because of orthodontic reasons were used.

Exclusion criteria:

Presence of any microcracks in root, root caries, immature apices, curved canal, calcified canal, accessory canals was excluded.

\section{Method of sample preparation:}

1. 80 , freshly extracted mandibular premolars were used in the present study ${ }^{\text {fig } 3}$. Roots of all teeth were cleansed with periodontal curettes followed by storage in $10 \%$ buffered formaline until used $^{\text {fig } 4}$.

2. Decoronation was done with respect to all the teeth with the help of slow speed diamond disk under water cooling by adjusting the length of roots up to $13 \mathrm{~mm}$ from the apex ${ }^{\text {fig }} 6$.

3. Preoperative radiographs were taken for all teeth to confirm single canal in each tooth sample ${ }^{\text {fig } 8}$. All teeth were examined for any root fracture, microcracks or craze lines under stereomicroscope ${ }^{\text {fig } 9}$.

4. mesiodistal and buccolingual coronal diameter of all roots were measured ${ }^{\text {fig } 10}$. The working length of roots was determined by \#10 k file, for preparation of glide path. All teeth were instrumented up to a master file of size 20/.04 mm taper with rotary file system ${ }^{\text {fig } 12}$.

5. Then, canals were prepared by using SAF and were irrigated by $3 \%$ of sodium hypochlorite solution and for smear layer removal rinsed with $17 \%$ of EDTA for 1 minute and final rinsed with $10 \mathrm{ml}$ of saline and dried with absorbent paper points ${ }^{\text {fig13 }}$.

6. All root samples were obturated according to the different obturation techniques with gutta percha and AH Plus sealer. Sealers used were manipulated as per the manufacturer instructions and coated over the canal wall with lentulo-spiral $^{\text {fig } 15}$.

7. Twenty teeth were randomly selected as control group and remaining 60 teeth were subdivided into 3 groups, 20 teeth in each group ${ }^{\text {fig } 14}$.

1. GROUP 1- Roots were prepared by SAF but not filled (control group).

2. GROUP 2- Roots were prepared by SAF and obturated with cold lateral condensation technique.

3. GROUP 3- Roots were prepared by SAF and obturated with warm vertical compaction technique. 
4. GROUP 4- Roots were prepared by SAF and obturated with thermafil technique.

Radiographs were taken to confirm the proper filling or presence of voids in roots ${ }^{\text {fig } 16}$. Then, coronal $1 \mathrm{~mm}$ of filling material were removed and filled with temporary filling material ${ }^{\text {fig } 17}$.

Then, teeth were stored at 37 degree celsius and 100\% humidity in incubator for 7 days to allow the sealers to set $^{\text {fig18 }}$.

To simulate the periodontal membrane apical $5 \mathrm{~mm}$ of all roots were covered by base plate wax to obtain $0.2-0.3 \mathrm{~mm}$ thick layer ${ }^{\text {fig } 19}$. Then, roots were mounted vertically in copper ring filled with self cure acrylic resin exposing $8 \mathrm{~mm}$ of coronal part of tooth. As soon as polymerization of acrylic resin starts, roots were removed from the resin and the base plate wax which covered the root surfaces, were removed ${ }^{\text {fig } 20}$.

Then, a thin layer of extra light body impression material was applied into the space created in acrylic resin mould and roots were again being embedded in acrylic resin till the setting of material ${ }^{\text {fig } 21}$.

Then, acrylic blocks were placed on lower plate of UTM machine with upper plate consisting of a spherical steel tip of $3 \mathrm{~mm}$ diameter. Tip was centered over the canal orifice, with slowly increasing vertical force of $1 \mathrm{~mm} / \mathrm{min}$ until fracture of root not analyzed ${ }^{\text {fig } 23}$.

When sudden drop in force was occurred on monitor then the value of force in Newton was recorded.

\section{Fig.1- FLOWCHART DEPICTING THE STUDY METHODOLOGY}

80 freshly extracted human single rooted mandibular premolars were included and stored in $10 \%$ buffered formalin.

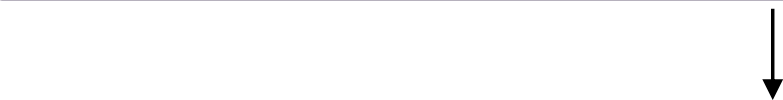

All teeth were examined under operating microscope to exclude any teeth with root caries, cracks or fractures. Preoperative radiograph were taken to confirm single canal in each tooth sample.

Samples were decoronated using a diamond disc with sufficient water cooling for standardizing the root length up to $13 \mathrm{~mm}$. Mesiodistal and buccolingual coronal diameter of roots were measured by caliper.

The working length of roots was determined by \# $10 \mathrm{k}$-file, glide path for SAF was achieved by a master file of size 20/.04 mm taper rotary instrument.

Root canals were prepared by SAF, irrigated by $4 \mathrm{ml}$ of $5.25 \%$ sodium hypochlorite solution and rinsed with 3 $\mathrm{ml}$ of $17 \%$ EDTA for smear layer removal and $10 \mathrm{ml}$ of saline as final rinse.

All 80 teeth samples were subdivided into 4 groups, 20 teeth in each group 


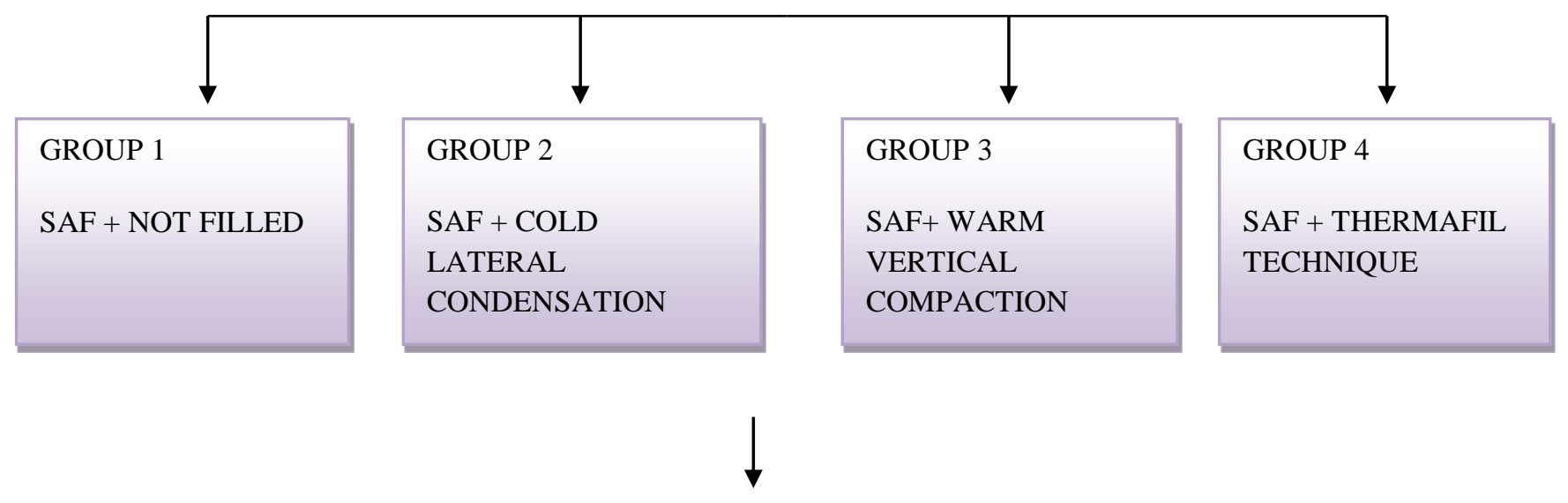

Radiographs were taken to confirm the proper filling of material. $1 \mathrm{~mm}$ of coronal filling material was removed and filled with temporary filling material. Samples were stored at 37 degree Celsius at $100 \%$ humidity for 7 days in incubator to allow the setting of the sealers.

To simulate the periodontal membrane apical $5 \mathrm{~mm}$ of all roots were covered by base plate wax mounted vertically in copper ring filled with self cure acrylic resin exposing $8 \mathrm{~mm}$ of coronal part of root

As soon as polymerization of acrylic resin started, roots were removed with baseplate wax covering the root surface. A thin layer of extra light body impression material was applied and roots were again being embedded in acrylic resin till the setting of material. diameter. Tip was centered over the canal orifice, with slowly increasing vertical force of $1 \mathrm{~mm} / \mathrm{min}$ until fracture was observed.

When sudden drop in force was observed then, value in Newton was recorded. Then, data collected was statistically analyzed. 


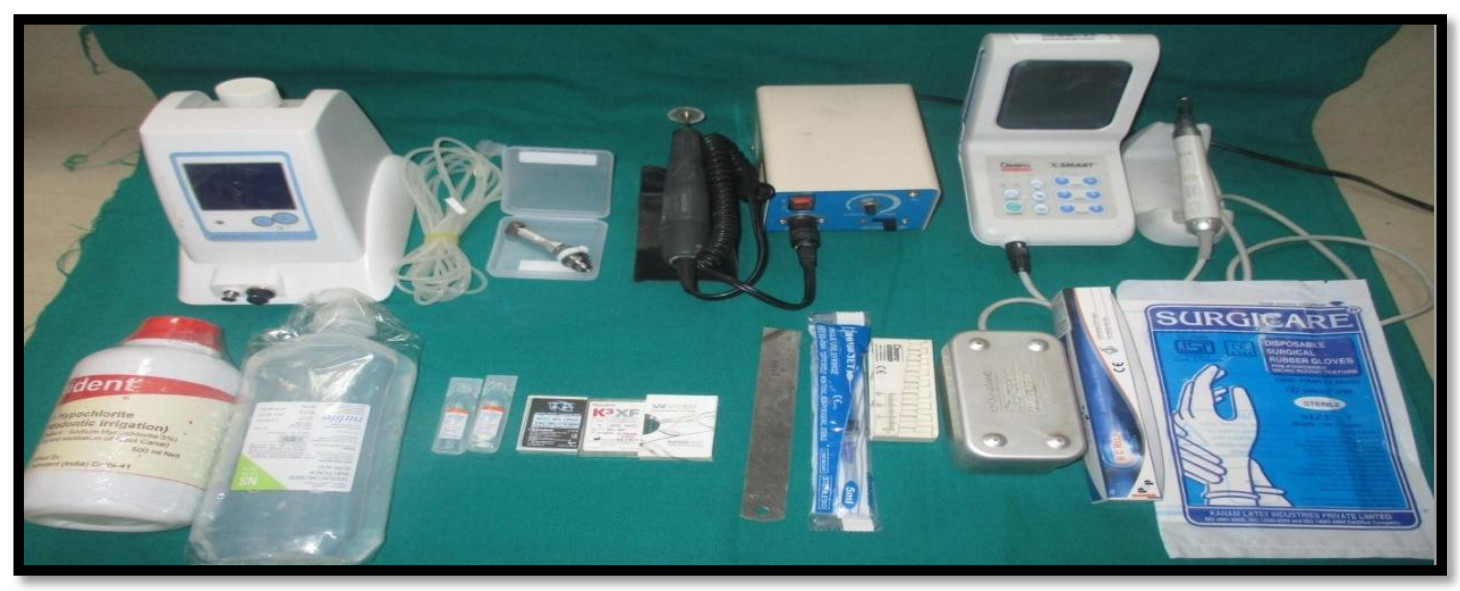

Fig 2:-Instruments And Material Used In Study

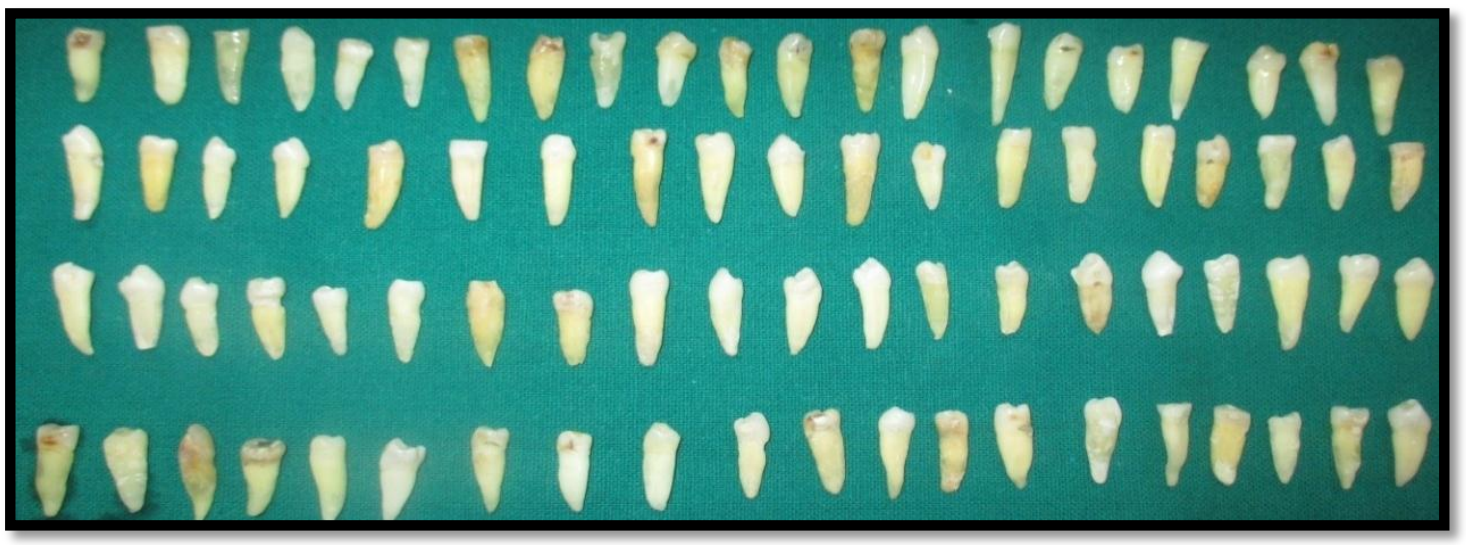

Fig 3:-Sample Size Of Extracted Human Mandibular Premolars

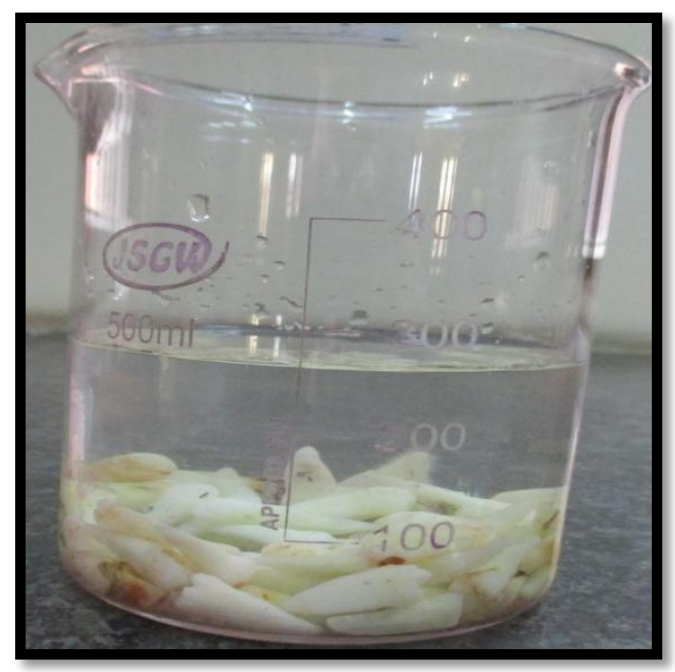

Fig 4:-Storage Of Samples In 10\% Buffered Formalin 


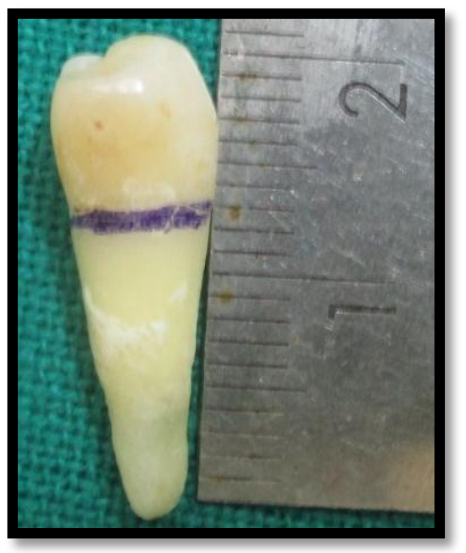

Fig.5:-Adjusting Length Up To 13mm Prior To Decoronation

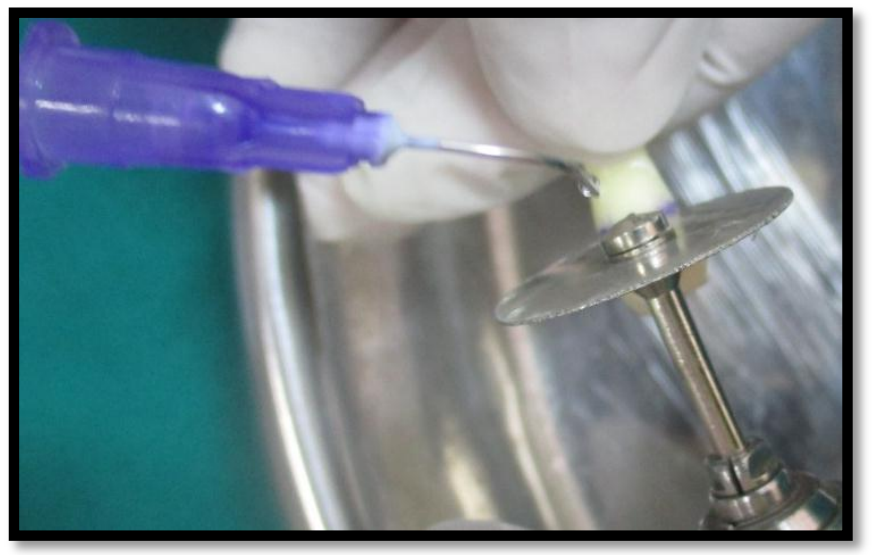

Fig 6:-Decoronation With Diamond Disc Under Water Cooling

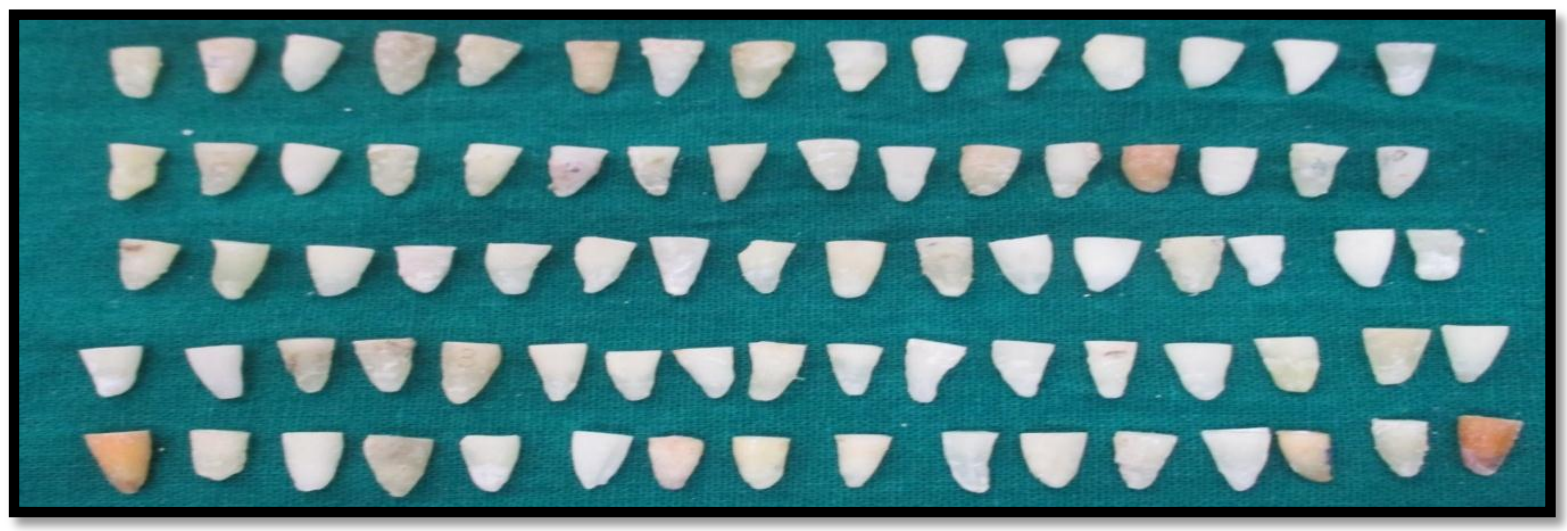

Fig 7:-Decoronated Teeth Samples 


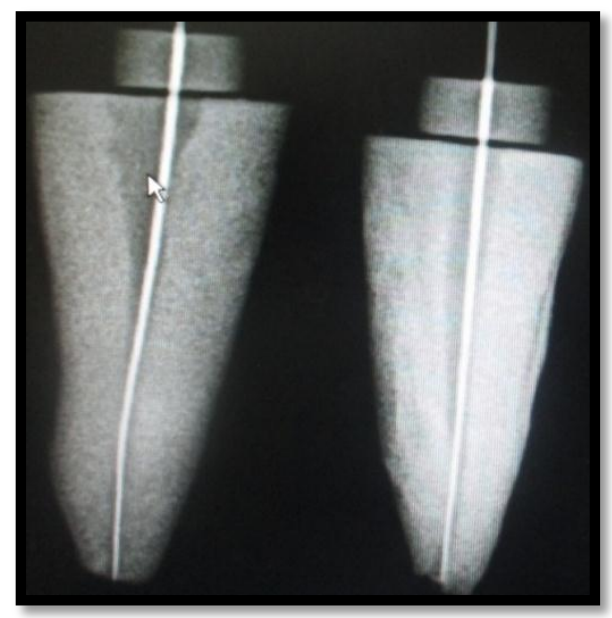

Fig 8:-Preoperative Radiograph Taken To Confirm Single Canal

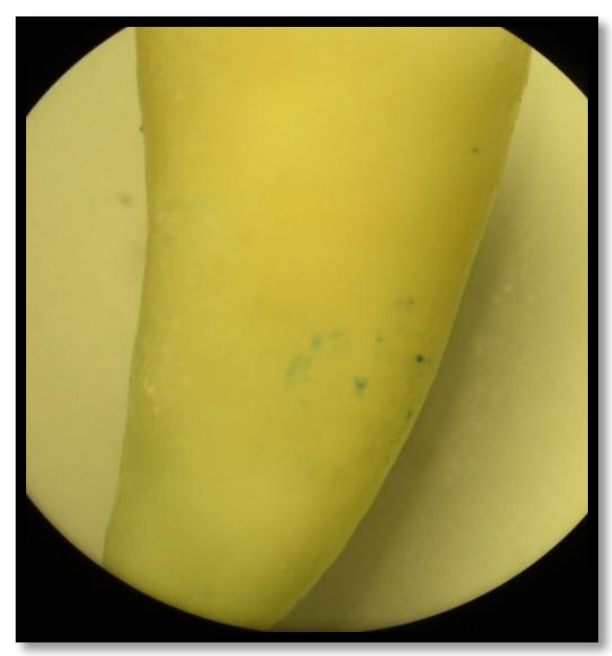

Fig 9:-Stereomicroscopic Image To Check Any Microcrack Or Craze Lines

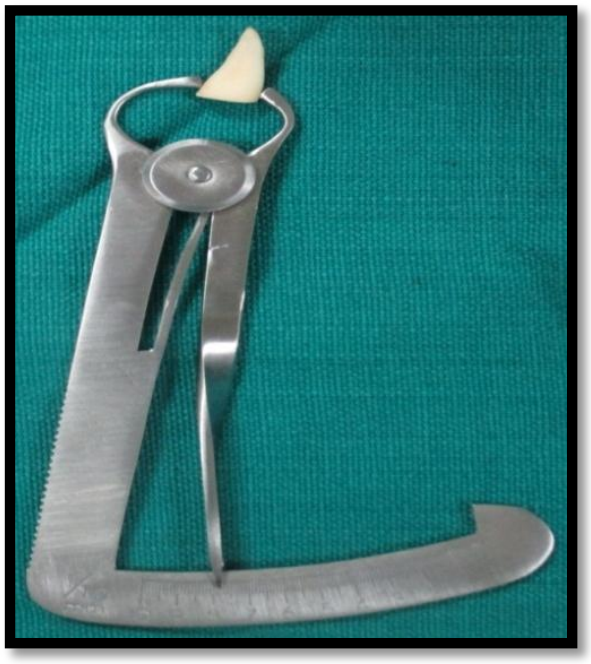

Fig 10:-Measuring Mesio Distal And Bucco Lingual Diameter Of Roots With Caliper 


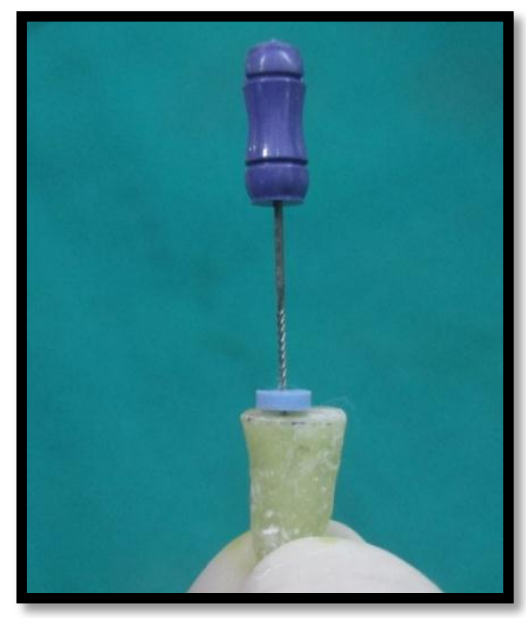

Fig 11:-Working Length By \#10 K-File

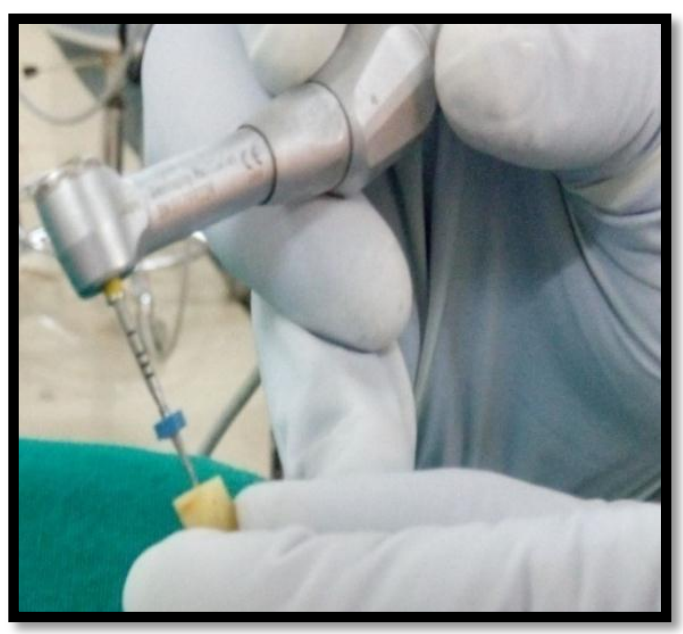

Fig 12:-Glide Path By Master File Size 20/.04mm Taper With Rotary File
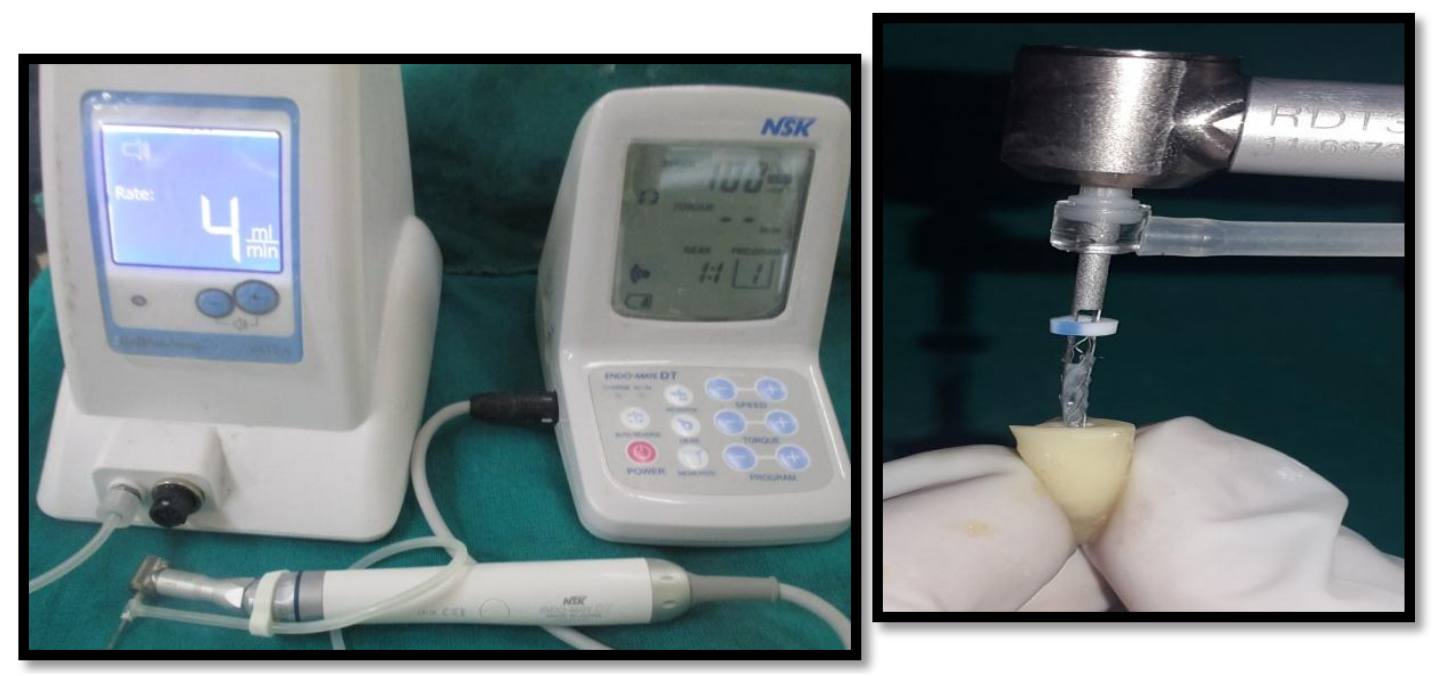
Fig 13:-All Roots Were Prepared By Saf And Irrigation With 3\% Naocl And 17\% Edta Then Final Rinsed With Saline.

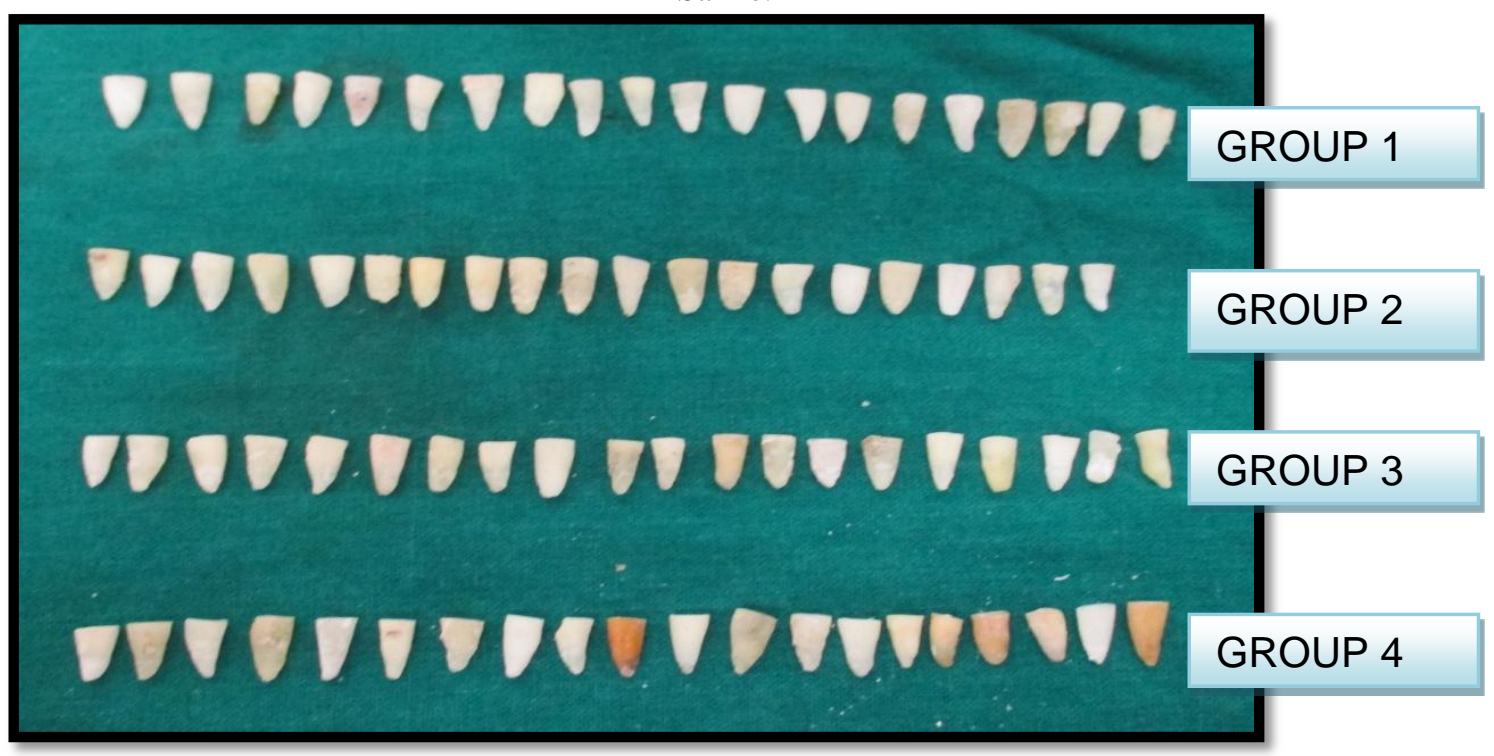

Fig 14:-Random Grouping Of Root Samples For Obturation
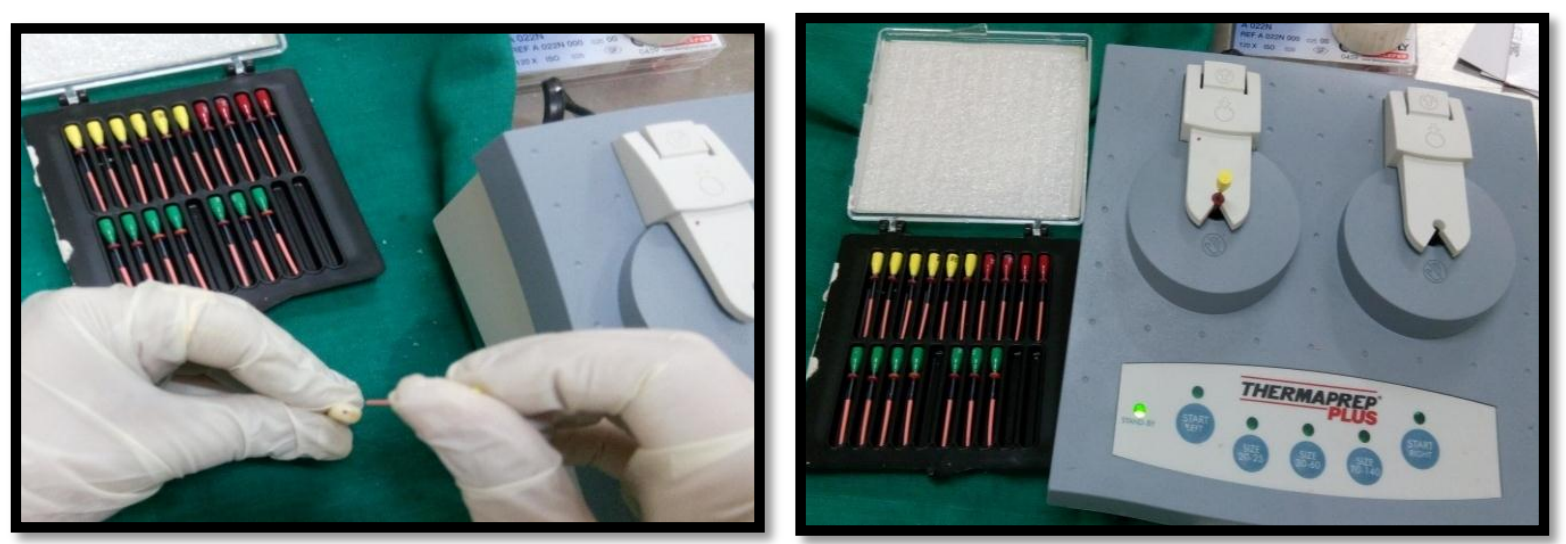

Thermafil Obturation
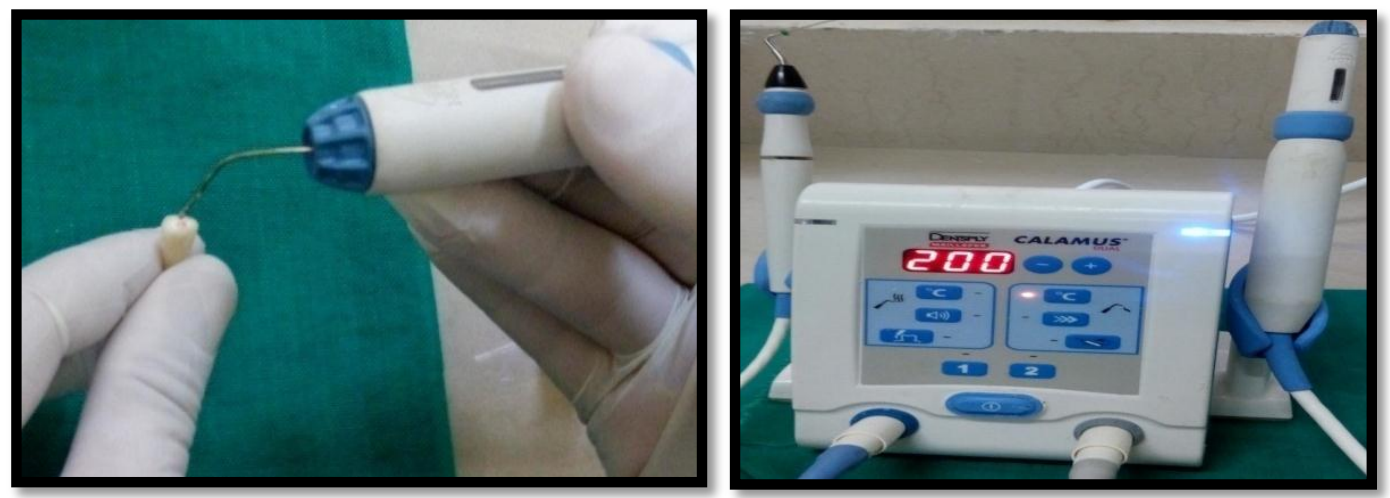

Warm Vertical Obturation Using Calamus System 


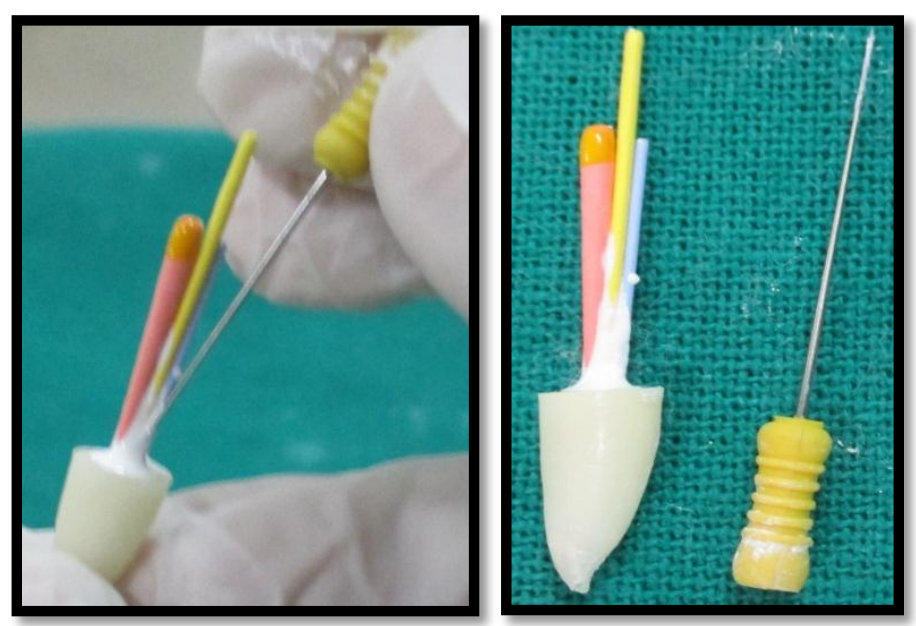

Cold Lateral Condensation Technique

Fig 15:-Obturation Of Canals With Three Different Obturation Tecnniques

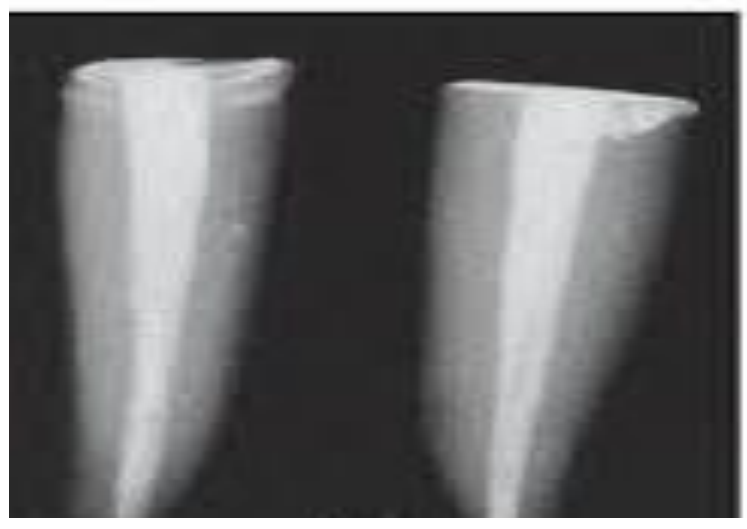

Fig 16:-Post Obturation Radiograph To Confirm The Proper Filling
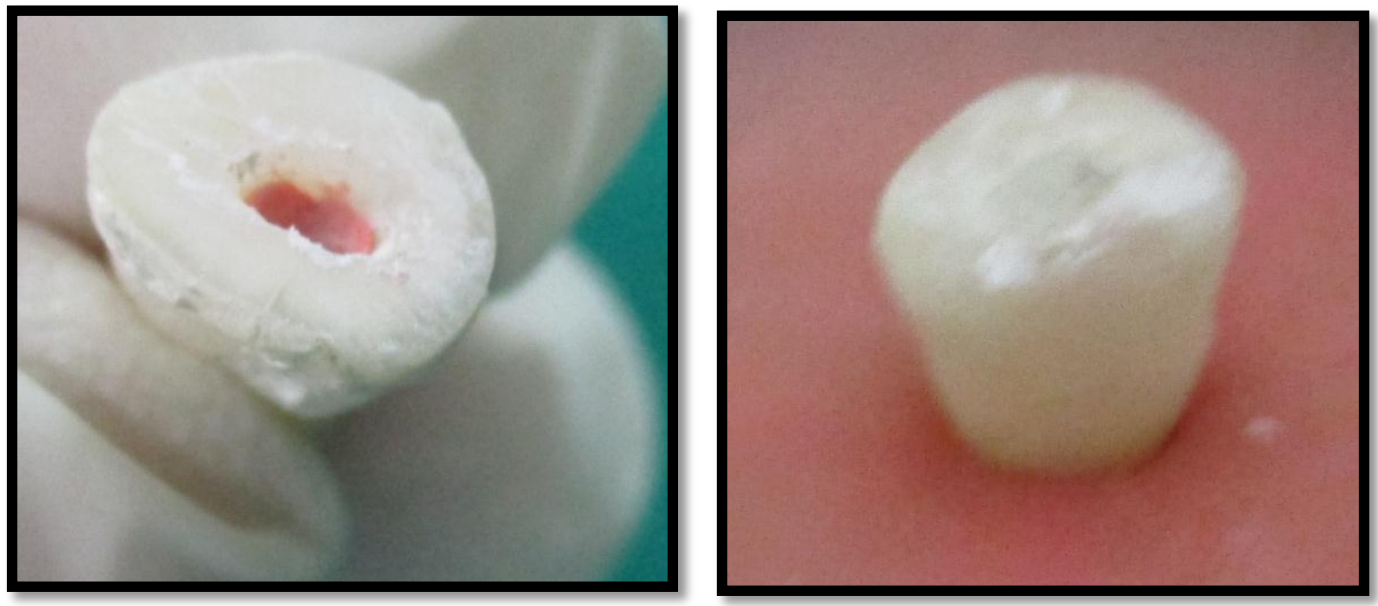

Fig 17:-Coronal 1mm Of Filling Material Replaced By Temporary Filling Material 

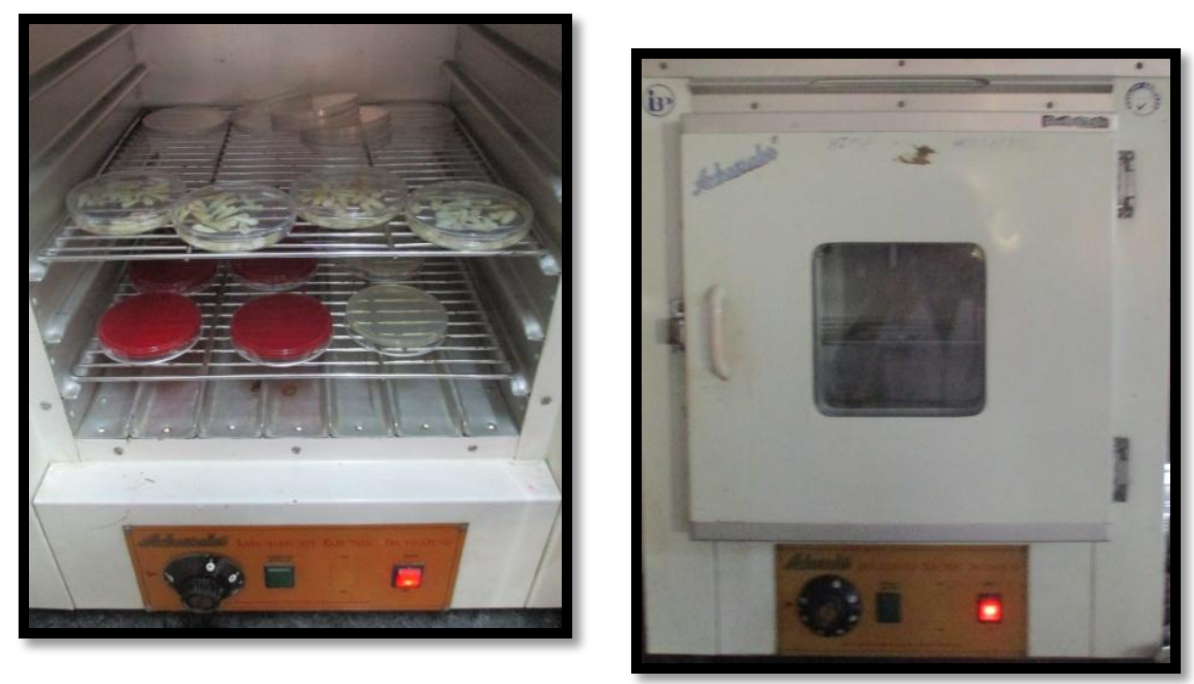

Fig 18:-Stored Teeth In Incubator At $37^{\circ} \mathrm{C}$ In $100 \%$ Humidity For 1 Week
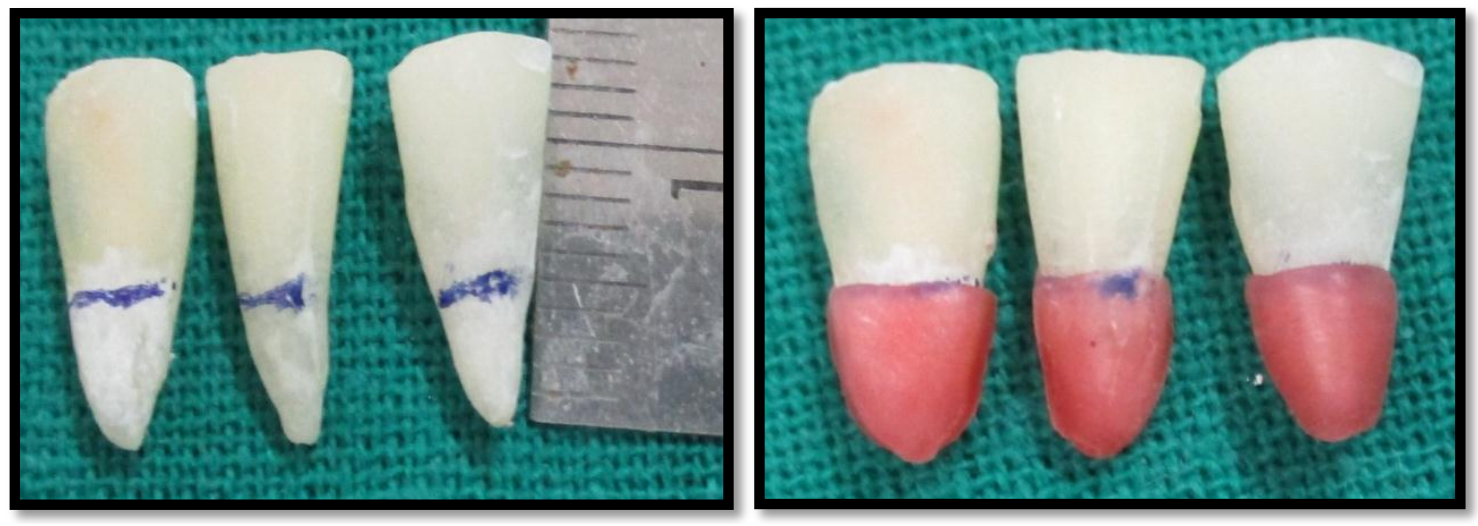

Fig 19:-5mm Of Roots Were Covered With Base Plate Wax To Create 0.2-0.3mm Of Pdl Space
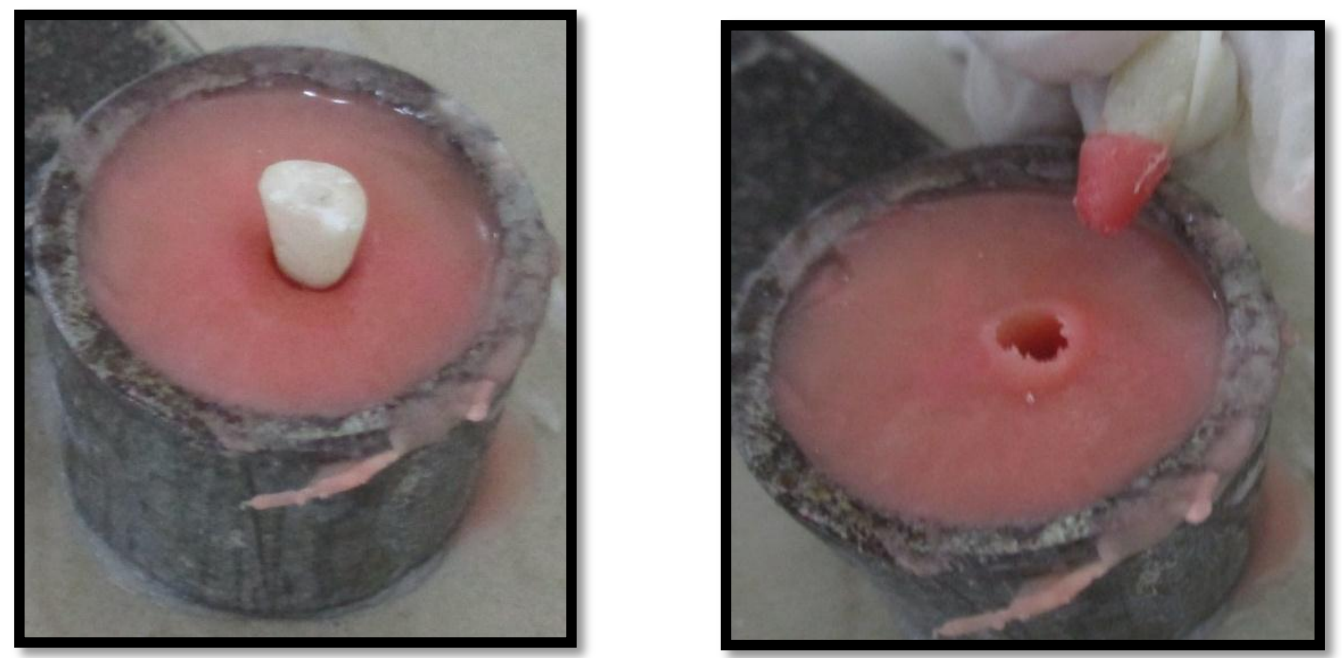
Fig 20:-After Mounting Of Roots In Acrylic Resin, As Soon As Polymerization Starts Roots Were Removed From The Resin To Remove The Base Plate Wax.
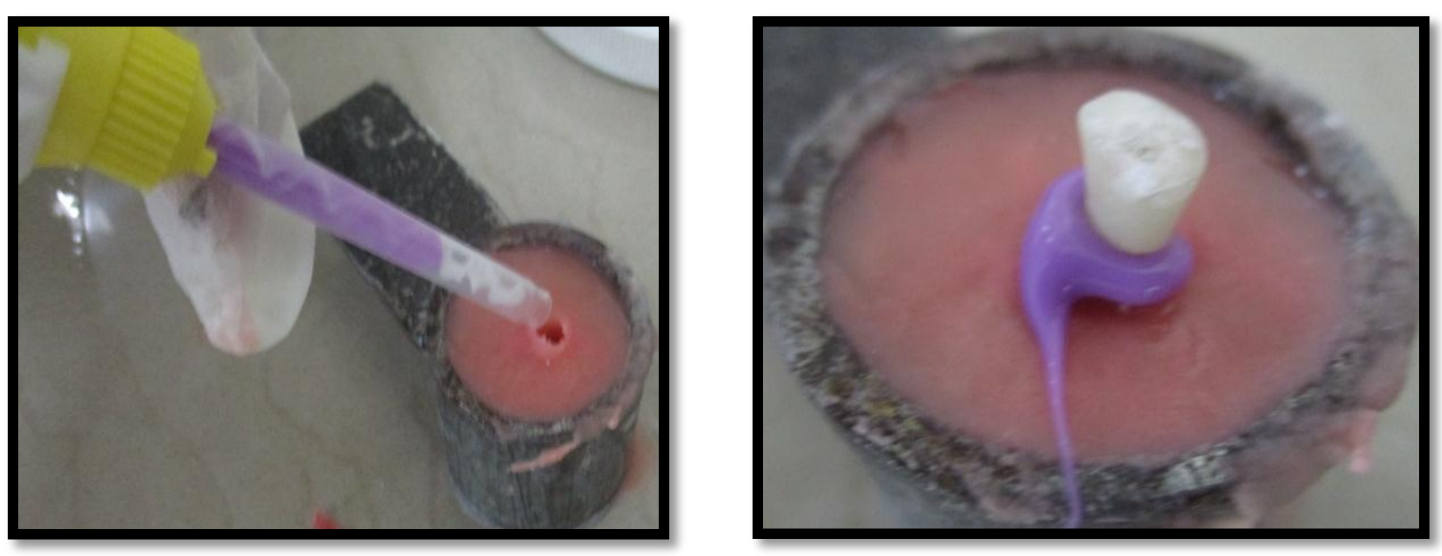

Fig 21:-A Thin Layer Of Extra Light Body Impression Material Was Applied To The Space Created In Resin Then Roots Were Reinserted Into The Spase Till The Setting Of Material

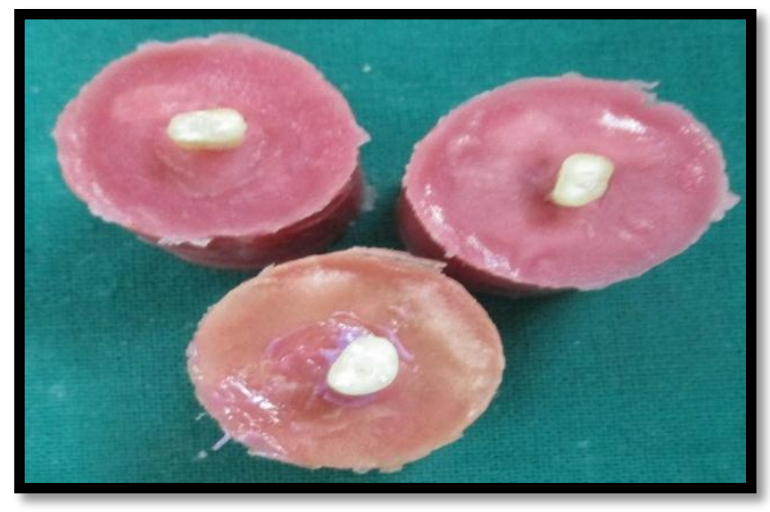

Fig 22:-Acrylic Block Samples

\section{Statistical evaluation:}

The statistical analysis was performed by the SPSS program for windows, version 17.0 (SPSS, Chicago,Illinois). All the values of four groups were expressed in terms of mean \pm SD, with significant differences among all groups.

All the values of four groups were evaluated statistically using one-way ANOVA and the unpaired t-test to determine the significance of the difference between different groups. For all statistical tests, a 'p' value less than 0.05 was taken to indicate a significant difference. 


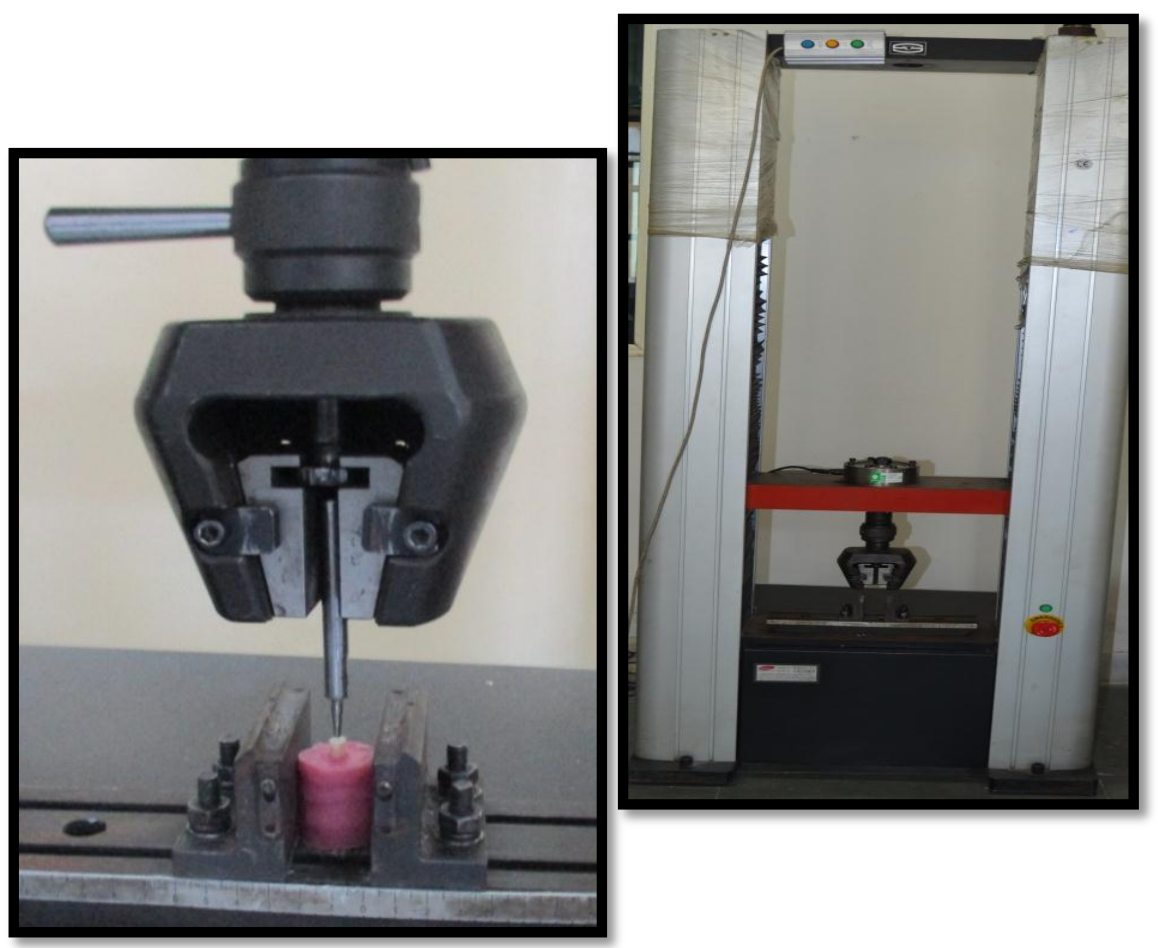

Fig 23:-Acrylic Blocks Were Placed On Lower Plate Of Utm With Upper Plate Consisting Of Spherical Steel Tip Of $3 \mathrm{~mm}$ Diameter, Centred Over The Canal Orifice With Slowly Increasing Vertical Force Of $1 \mathrm{~m} / \mathrm{Min}$ Until Fracture Is Observed
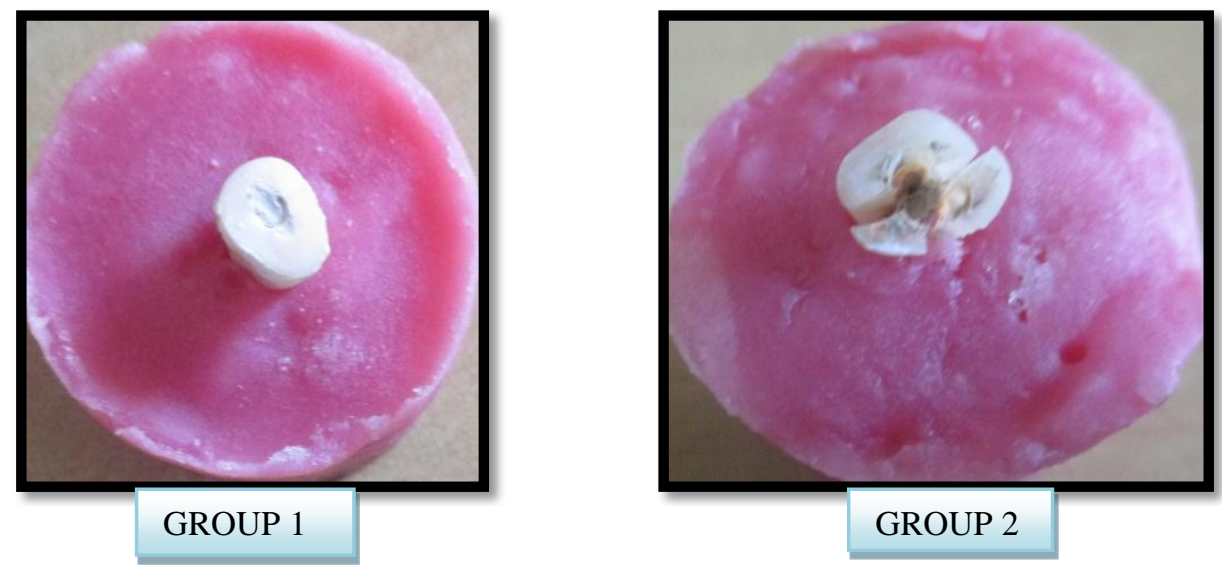

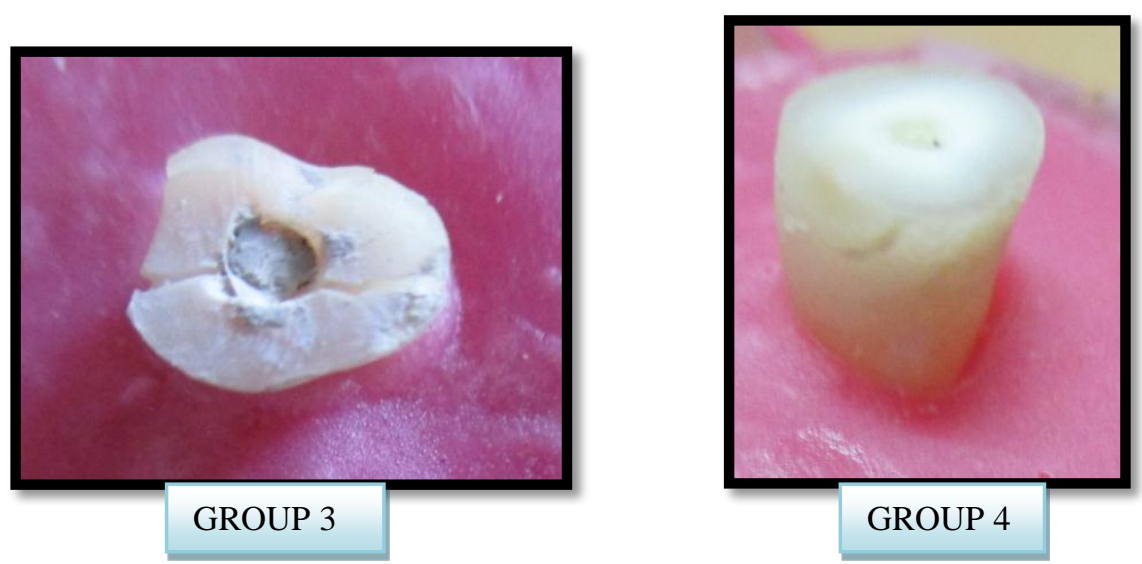

Fig 24:-Fractured Tooth Samples After Utm Test For Fracture Resistance

\section{Discussion:-}

Vertical root fracture (VRF) is a challenging complication that may occur during or after root canal treatment procedures. The prognosis of a root-filled tooth having VRF is poor. There are several predisposing factors for VRF, including loss of tissue, dehydration of dentin, undesirable effects of irrigation solutions, and excessive pressure during filling procedures. Lateral compaction of gutta percha is used widely for root canal filling and was reported previously to be associated with an increased risk of VRF. Recently, it has been reported that root canal filling procedures can potentially propagate cracks in the apical region. However, numerous studies concluded that the load generated during lateral condensation is generally less than the load required to fracture the roots except in cases of very weak roots 6 . Thus, it has remained unclear whether root canal filling can cause VRF.

The diameter of the prepared canal is another potential factor that could affect the tendency of VRF. Excessive taper may result in excessive removal of dentin and weakening of the root. Over the last decades, technological advancements in rotary nickel-titanium instruments have led to new design concepts and easier, faster, and better root canal shaping. ProTaper rotary files (Dentsply Maillefer) have an increasingly tapered design that enables active cutting motion and removes relatively more dentin coronally, which affect the strength of root ${ }^{8}$.

This led to the recent introduction of a new self-adjusting file (SAF) which is a hollow file signed as a compressible, thin-walled, pointed cylinder composed of a thin NiTi lattice which not only adapts itself longitudinally to a curved canal, as most rotary nickel-titanium files do, but also adapts itself to the cross-section of the canal. Rather than machining each canal into one with a circular cross-section, it removes an even dentin layer from all around the root canal, thus respecting the shape of a given root canal rather than imposing a circular cross-section on every canal no matter what its shape.

The SAF file touches the inner canal wall in all points as a result of compressible and expansive structure of lattice. This characteristic might not create any microcrack in dentine because of the inhibition of stress formation along the root canal. Additionally, the surface of the lattice thread is lightly abrasive, which allows it to remove dentine with a back and forth grinding motion rather than the machining action with the rotary blade of the NiTi rotary files ${ }^{5}$. On the other hand, rotary files may reduce the thickness of the remaining dentine on the inner side of the curvature to such an extent that it increases the risk of vertical root fracture.

Therefore, this was the reason why SAF system was used in this study rather than any other rotary file for preparation of canals with less dentinal damage which leads to negligible effect on fracture resistance of teeth. In current study, we have used three different obturation techniques to fill the canals i.e cold lateral compaction, warm vertical condensation and thermafil technique, due to the frequent use of these techniques in root canal treatment.

Lateral compaction of gutta percha is widely used to fill the root canal system and was previously reported to be associated with an increased risk of VRF. Some studies suggested that the spreader design and applied forces during gutta percha cones compaction may be the contributing factor the appearance of VRF. The potential for VRF is also 
present with warm vertical compaction as the forces assumed to be equal to the forces of lateral compaction or slightly different ${ }^{7}$.

Whereas, the other techniques like thermafil technique in which spreaders or pluggers are not used, is meant to create less wedging effect on root then other two techniques and decrease the fracture resistance of roots.

In this present study we have evaluated the fracture resistance of teeth, prepared by SAF. An in vitro model was developed which simulate the clinical conditions.

In this study single rooted mandibular premolars extracted due to orthodontic reason was taken and stored in $10 \%$ buffered formalin until used, as this storage medium shows negligible effect on dentine micro hardness ${ }^{9}$.Then, teeth were decoronated with low speed diamond disk for all groups with continuous water cooling to avoid heat production which may affect the dentine and samples were seen under stereomicroscope to check for any microcracks, if it was present then tooth was discarded. All roots were prepared with SAF as per the manufacturer instructions; this system was used in this study as it assumed to cause least effect on teeth fracture resistance ${ }^{5}$.

Saunders et al ${ }^{10}$ proposed a alternating or simultaneous use of $3 \% \mathrm{NaOCl}$, mainly during canal preparation with $17 \%$ EDTA as final flush, effective in removing smear layer.

In accordance to this, irrigation with $4 \mathrm{ml}$ of $3 \%$ of $\mathrm{NaOCl}$ followed by $3 \mathrm{ml}$ of $17 \%$ of EDTA for 3 mins, then final flush with $10 \mathrm{ml}$ of normal saline was done with respect to each tooth.

Then, three different obturating techniques were used i.e cold lateral compaction, warm vertical and thermafil.

Cold lateral compaction technique was assumed to cause more forces on root canal during the obturation. In this technique spreaders are used to compact the gutta percha cones which create lateral forces on root canal and may lead to micro cracks ${ }^{6}$.

But some authors suggested that the forces applied in warm vertical condensation can cause wedging effect on root canal and affect the fracture resistance of $\operatorname{root}^{11}$.

Thermafill technique was used in comparison with other two obturation techniques to evauate the effect of different obturation techniques on root canal fracture resistance.

After obturation, teeth were incubated in incubator at $37^{\circ} \mathrm{C}$ in $100 \%$ humidity for 7 days. Because according to some author's sealers required the presence of humidity to set and harden ${ }^{12}$.

All roots were embedded in acrylic resin with $0.2-0.3 \mathrm{~mm}$ coating of extra light body impression material around the $5 \mathrm{~mm}$ of root apex, to replicate the PDL and give the cushioning effect to the teeth during the force applied on teeth.

Then, all acrylic blocks placed over lower plate of UTM and a $3 \mathrm{~mm}$ spherical tip centred over the canal orifice with slowly increasing vertical force of $1 \mathrm{~m} / \mathrm{min}$ until fracture is observed.

Force applied by UTM was immediately stopped as the drop in graph on monitor was recorded which was attached to the machine. Block was removed as it is and same procedure done with other samples and amount of force applied in Newton was recorded for each group.

In the current study between group comparisons of yield load revealed that group 1 (control group) had significantly higher values As compared to all other groups. Group 2 (lateral compaction) had significantly lowest value as compared to Group 3 (warm vertical) and Group 4 (thermafil).

Thus it may be inferred that cold lateral compaction technique decreases much more fracture resistance of teeth as compared to thermafil and warm vertical condensation.

This shows that the forces applied during the cold lateral compaction can increase the risk VRF, irrespective of that the teeth was prepared by SAF which cause negligible effect on root canal. 
Warm vertical condensation shows decrease in fracture resistance then thermafil, because it is assumed that pluggers are used to condense the GP into the canal which creates forces on to the root canal.On other hand, in thermafil no such spreaders or pluggers are used to compress the GP, so it shows better result than Group 1 and Group 2.

Group 1 which shows the excellent fracture resistance depicting that the SAF has very negligible effect on fracture resistance of root, as we already discussed its thin, compressible, hollow abrasive design provide minimal loss of dentine during the preparation.

On the basis of the findings presented herein and within the limitations of this study, it may be concluded that cold lateral compaction technique had a highest effect on fracture resistance of teeth than warm vertical condensation and thermafil technique.

\section{Review Of Literature Oliveira FC,Deneny GE,Boyer DB $(1987)^{3}$ :}

Compared the resistance to fracture of endodontically treated premolars with modified types of cavity preparation followed by different methods of restoration. They concluded that the greatest factor influencing strength of the endodontically treated premolars in the study was the remaining tooth structure. The preservation of all remaining sound dentin should be a primary objective in preserving tooth strength. Restoration of endodontically treated teeth was much weaker then unprepared teeth.

\section{Saw LH, Messer HH (1995) ${ }^{30}$ :}

They evaluated the influence of different obturation techniques (lateral condensation, Obtura, and Thermafil) on root strains, was assessed in 27 upper central incisors. They concluded that the technique of obturation significantly influenced the root strains, with the Obtura generating the highest strains. The Thermafil group showed significantly less strain than the Obtura or lateral condensation groups. Thermal expansion of dentin was an unexpected finding. A large proportion of strain in the Obtura and Thermafil groups was found to be thermal strain. The mean load required to cause vertical root fracture was five to six times higher than the load used in obturation.

\section{Wilcox LR, Roskelley C, Sutton T (1997) ${ }^{1}$ :}

Evaluated the effect of lateral condensation forces on the development of vertical root fracture (VRF) in teeth that have undergone controlled, measured internal root reduction (i.e. canal preparation). They concluded that the stresses generated from inside the root canal are transmitted through the root to the surface where they overcome the bonds holding the dentin together. The roots in this study all developed numerous craze lines, but none had more than one fracture. This probably indicates that stresses are released at one site (by fracturing) and are incapable of being generated at other sites once fracture has occurred.

\section{Blum JY, Parahy E, Micallef JP (1997) ${ }^{11}$ :}

Determined and display the vertical and lateral forces developed during an obturation using the warm vertical compaction technique. No significant difference was found for the forces exerted over the course of the obturation. The mean value of the lateral forces was $0.85+-0.2 \mathrm{~kg}$. The mean duration of compaction was, respectively, 2.03 ${ }_{+} 0.13$ min for the apical packing and $5+$ I s for filling of the remainder of the canal.

\section{Lertchirakarn V, Palamara JE, Messer HH(1999) ${ }^{27}$ :}

They evaluated the vertical loads and root surface strains in extracted teeth during lateral condensation using finger and hand spreaders. All teeth were measured and compared the loads and strains at fracture. Then the results suggest that lateral condensation alone should not be a direct cause of vertical root fracture. The use of finger spreaders, however, is associated with lower risk.

\section{Lertchirakarn V, Timyam A, Messer HH (2002) ${ }^{2}$ :}

Compared vertical forces at fracture of endodontically treated mandibular incisors obturated with different types of root canal sealer. They concluded that Force at fracture of roots obturated with Ketac-Endo was significantly higher than those obturated with AH Plus and Tubliseal. Most fracture lines were in a buccolingual direction. The results suggested that Ketac-Endo strengthens endodontically treated roots and may be used for weak roots, which are likely to be susceptible to vertical root fracture. 
Wu MK, Van Der Sluis LW, Wesselink PR (2004) ${ }^{28}$ :

Compared the force required to vertically fracture uninstrumented and instrumented mandibular premolars and canines. They concluded that the instrumented mandibular premolars have a higher risk to fracture than the uninstrumented mandibular premolars.

Lee JJ, Nettey-Marbell A, Cook A et al (2007) ${ }^{9}$ :

Conducted a study to test the null hypothesis that the storage medium and sterilization method have no effect on composite-to-dentin bond strengths. They concluded that the Storing bovine teeth in 5.25 percent NaoCl may negatively affect composite-to-dentin bond strengths. Immersion in 10 percent formalin might be the best option for storage and sterilization of bovine teeth that are to be used in dental bonding studies in vitro.

Sagsen B, Er O, Kahraman Y, Akdogan G (2007) ${ }^{24}$ :

Compaired the fracture resistance of roots filled with different materials. They concluded that all the materials used in the study reinforced the prepared root canals, i.e resilon cones and Epiphany sealer, gutta-percha and AH 26, gutta-percha and MCS Canal Sealer.

Pişkin B, Aydın B, Sarıkanat M (2008) ${ }^{13}$ :

Assessed the effect of spreader size used during cold lateral compaction of gutta-percha on fracture resistance of roots in maxillary incisor teeth. They concluded that the size of the initial spreader may be important to prevent extra loading. The present study revealed that spreader size equal to the master apical file decreased the fracture resistance of maxillary incisor roots.

\section{Shemesh H, Bier CA, Wu MK (2009) ${ }^{16}$ :}

They evaluated the incidence of defects in root dentine before and after root canal preparation and filling. They concluded that the Root canal preparation and filling of extracted teeth created dentine defects such as fractures craze lines and incomplete cracks.

\section{Karapinar Kazandag M, Sunay H, Tanalp J, Bayirli G (2009) ${ }^{23}$ :}

Evaluated the fracture resistance of teeth filled with various canal filling materials. They concluded that the systems aiming to obtain a monoblock system were not superior to the conventional AHPlus + Gutta-percha technique in terms of fracture resistance. The fracture resistance of roots using ActiV GP + lateral compaction Gutta-percha was significantly reduced compared with the AH-Plus + Guttapercha group.

Shemesh H, Wesselink PR, Wu MK (2010) ${ }^{15}$ :

Compared the incidence of dentinal defects (cracks and craze lines) after root canal preparation, lateral compaction and continuous wave compaction of gutta-percha and AH26 sealer. They concluded that the dentinal defects were observed in roots filled with gutta-percha and AH26 using the lateral compaction and continuous wave techniques.

Versiani MA, Pécora JD, de Sousa-Neto MD $(2011)^{21}$ :

Evaluate the root canal preparation in flat-oval canals treated with either rotary or self-adjusting file (SAF) by using microtomography analysis. They concluded that, by using SAF instruments, flat-oval canals were homogenously and circumferentially prepared. The size of the SAF preparation in the apical third of the canal was equivalent to those prepared with \#40 rotary file with a 0.02 taper.

Kaya S, Yiğit-Özer S, Adigüzel Ö(2011) $)^{22}$ :

Evaluated Self-Adjusting File (SAF) in the removal of smear layer and impact on the dentin surface using sodium hypochlorite $(\mathrm{NaOCl})$ as an initial irrigation solution at 3 different concentrations combined with $1 \%$ EDTA. In addition, the erosive effect of this dual irrigation regime was examined. They concluded that when using the SAF with continuous irrigation and vibration lower concentrations of $\mathrm{NaOCl}$ and EDTA can be recommended for efficient clinical removal of the smear layer even in the apical thirds and to avoid excessive erosion of root dentin.

Yoldas O, Yilmaz S, Atkan G et al (2012) ${ }^{5}$ :

Compared the dentinal microcrack formation while using hand files (HFs), 4 brands of nickel-titanium (NiTi) rotary files and the self-adjusting file. They concluded that all rotary files created microcracks in the root dentin, whereas the SAF file and hand instrumentation presented with satisfactory results with no dentinal microcracks. 
Topcuoglu HS, Arslan H, Keleş A, Koseoglu M (2012) ${ }^{14}$ :

Compared in vitro root fracture resistance following root canal filling with AH 26 using lateral condensation, BeeFill, and Thermafil techniques. They concluded that, the results indicate that instrumentation of root canals had a significant effect on fracture resistance $(\mathrm{p}<0.05)$. In addition, there were no differences between the root canal obturation techniques;furthermore, these techniques did not create a statistically important resistance to vertical fracture.

Bhat SS, Hegde SK, Rao A, Mohammed AS (2012) ${ }^{42}$ :

Compared the ex-vivo effects of different root canal sealers on the fracture resistance of endodontically treated teeth. They concluded that both the resin based sealers that were used in this study were equally effective compared to that of the zinc oxide-based sealers and the control group. However, no significant results were obtained when the comparison was made between zinc oxide-eugenol and gutta-percha and the control group.

Shaheen NA, Farag AM, Alhadainy HA, Darrag AM (2013) ${ }^{17}$ :

Evaluated the fracture resistance of endodontically treated roots using different root canal preparation/obturation combinations including ProTaper, RaCe and hand preparation systems combined with Soft-Core/AH26, RealSeal and EndoREZ. They concluded that there is no significant difference among the obturation systems was recorded however a significant difference with the control subgroup (ID) prepared with ProTaper was obvious.

Kumaran P,Sivapriya E,Indhramohan J, Gopikrishna V (2013) ${ }^{7}$ :

Evaluated the role of rotary root canal instrumentation followed by obturation with three different techniques and two different materials on the incidence of dentinal defects. They concluded that root canal instrumentation significantly influenced the incidence of dentinal defects or fracture. Dentinal defects were more significantly attributed to the role of root canal instrumentation rather than the type of obturation technique or material. Lateral compaction with Gutta-percha significantly produces more defects than passive Gutta-percha obturation.

Liu R, Hou BX, Wesselink PR et al (2013) ${ }^{20}$ :

Compared the incidence of root cracks observed at the apical root surface and/or in the canal wall after canal instrumentation with 3 single-file systems and the ProTaper system. They concluded that Nickel-titanium instruments may cause cracks on the apical root surface or in the canal wall; the Self-Adjusting File and Reciproc files caused less cracks than the ProTaper and OneShape files.

Secilmis A, Dilber E, Ozturk N, Yilmaz FG (2013) ${ }^{38}$ :

Evaluated the influence of different storage times and storage solutions on the mineral content of enamel. They concluded that the storage conditions significantly affected the levels of calcium, potassium, sodium, and phosphorus $(p<0.05)$. Storage procedures can significantly affect the calcium, potassium, sodium, and phosphorus contents of enamel.

Capar ID, Altunsoy M, Arslan H (2014) ${ }^{8}$ :

Evaluated the fracture strength of roots instrumented with the Self Adjusting File and the ProTaper system and filled with the cold lateral compaction technique. They concluded that Instrumentation with the SAF or the ProTaper rotary system did not change the fracture strength of standardized roots with respect to cross-sectional diameter and weight.

Metzger Z (2014) ${ }^{18}$ :

The aim of this review is to introduce the reader to the SAF System and its mode of operation. The challenges that remain unmet by the current rotary file systems will be discussed one by one, leading to the unavoidable conclusion that we do need a change of concept in root canal treatment. Consequently, the new concept of minimally invasive 3D endodontics has emerged, made possible by the new SAF technology. This concept aims to achieve all of the basic aims of root canal treatment without causing the unnecessary damage to the radicular dentin often observed in roots treated with traditional, old, or new rotary file instrumentation.

Pawar AM, Pawar SM, Pawar MG, Kokate SR (2014) ${ }^{39}$ :

Compared the fracture resistance of mandibular premolars, obturated after instrumentation by Self-Adjusting File (SAF), ProTaper NEXT (PTN) and WaveOne (WO).They concluded that both the resin based sealers that were used in this study were equally effective compared to that of the zinc oxide-based sealers and the control group. However, 
no significant results were obtained when the comparison was made between zinc oxide-eugenol and gutta-percha and the control group.

Aydin U, Aksoy F, Karataslioglu E, Yildirim C (2015) ${ }^{37}$ :

Evaluated the incidence of crack formation while using Reciproc, WaveOne and Twisted File Adaptive with and without ethylenediaminetetraacetic acid (EDTA) gel. They concluded that Control group did not reveal any cracks. Crack formation with three novel Ni-Ti instruments was similar. Using EDTA gel did not reduce crack occurrence.

Uzunoglu E, Yilmaz Z, Erdogan O, Görduysus M. (2016) ${ }^{43}$ :

Compared the effect of different final irrigation solutions on fracture resistance values (FRVs) of endodontically treated teeth. They concluded that Root canal preparation weakens the tooth. The final irrigation regimen has an impact on the FRV. A short time exposure to irrigation solutions (REDTA and QMix) that include surfactants probably contributed to the higher FRV, instead of a long time exposure as done with BioPure MTAD.

\section{Summary and Conclusion:-}

The strength of an endodontically treated tooth is related directly to the method of canal preparation and to the amount of remaining sound tooth structure. It is commonly believed that the loss of dentin creates an increased susceptibility to fracture. The reasons most often reported have been the water loss and loss of collagen crosslinking, excessive pressure during obturation and the removal of tooth structure during endodontic treatment.

This study deals with the evaluation of fracture resistance of the tooth prepared by Self Adjusting File and obturated with three different obturation techniques i.e cold lateral compaction, warm vertical condensation, and thermafil system.

80 extracted human mandibular premolars were selected randomly and distributed in four groups $(\mathrm{n}=20)$. All teeth were decoronated and canals were prepared by using SAF system and Irrigated with $3 \%$ of $\mathrm{NaOCl}$ and smear layer removed by using $3 \mathrm{ml} 17 \%$ EDTA.

The canals were filled with three different obturating techniques:

1. Group 1: Control group prepared by SAF but not filled

2. Group 2: Cold lateral compaction $+\mathrm{SAF}$

3. Group 3: Warm vertical condensation $+\mathrm{SAF}$

4. Group 4: Thermafil technique + SAF

All teeth were mounted vertically in self cure acrylic resin after simutlating the PDL.

The test specimens were subjected to the fracture resistance test method using Universal Testing Machine, at a cross head speed of $1 \mathrm{~mm} / \mathrm{min}$.

The fracture resistance were analyzed by one way analysis of variance (ANOVA) and the t- test for multiple comparison, with significance value of $\mathrm{p}<0.05$.

There was a significant difference among the tested groups. Highest mean value was recorded in group 1 i.e. control group and the lowest mean value of force applied recorded in group 2 i.e. cold lateral compaction technique. Whereas, there is not much difference in between group 2 and group 3 i.e. in cold lateral compaction and warm vertical condensation. But, group 4 (i.e. Thermafil system) showed a higher mean value then group 2 and group 3.

On the basis of the findings presented herein and within the limitations of this study, it may be concluded that Control group had highest fracture resistance, followed by Thermafil system then warm vertical condensation followed by cold lateral compaction. Cold lateral compaction had the lowest fracture resistance and control group had highest fracture resistance.

\section{Results:-}

All the four groups showed significant differences $(\mathrm{P}<0.05)$ in fracture resistance of teeth, these are as follows:

1. Group 1 showed significantly high mean value $(1.70 \mathrm{~N})$ than other groups.

2. Group 2 showed lowest mean value $(0.56 \mathrm{~N})$ than other groups.

3. Group 3 showed significantly higher mean value $(0.87 \mathrm{~N})$ than group $2(0.56 \mathrm{~N})$ and group $4(1.43 \mathrm{~N})$

4. Group 4 showed the significantly highest mean value $(1.43 \mathrm{~N})$ than group $2(0.56 \mathrm{~N})$ and Group $3(0.87 \mathrm{~N})$ 
Comparison in terms of fracture resistance revealed, higher fracture resistance in group 1 which was prepared by SAF but not filled.

Whereas, group 2 showed lowest fracture resistance, which is prepared by SAF and filled with cold lateral compaction technique.

Table 1:-Following Table Represents The Minimum Load In Newton Required To Fracture The Teeth In Each Group

\begin{tabular}{|r|r|r|r|}
\hline 1.982 & 0.606 & 0.917 & 1.411 \\
\hline 1.882 & 0.276 & 0.937 & 1.487 \\
\hline 1.732 & 0.874 & 0.853 & 1.489 \\
\hline 1.642 & 0.275 & 0.831 & 1.432 \\
\hline 1.999 & 0.287 & 0.937 & 1.495 \\
\hline 1.563 & 0.205 & 0.842 & 1.486 \\
\hline 1.789 & 0.269 & 0.961 & 1.597 \\
\hline 1.569 & 0.261 & 0.993 & 1.538 \\
\hline 1.497 & 0.496 & 0.942 & 1.678 \\
\hline 1.753 & 0.175 & 0.973 & 1.267 \\
\hline 1.987 & 0.176 & 0.539 & 1.378 \\
\hline 1.568 & 0.584 & 0.842 & 1.386 \\
\hline 1.403 & 1.121 & 0.853 & 1.587 \\
\hline 1.896 & 1.207 & 0.963 & 1.289 \\
\hline 1.987 & 0.276 & 0.831 & 1.267 \\
\hline 1.487 & 0.485 & 0.742 & 1.278 \\
\hline 1.268 & 1.302 & 0.842 & 1.209 \\
\hline 1.654 & 1.108 & 0.917 & 1.487 \\
\hline 1.597 & 1.242 & 0.916 & 1.428 \\
\hline 1.809 & 0.034 & 0.941 & 1.597 \\
\hline
\end{tabular}

Table 2:-Following Table Represents The Mean Force With Standard Deviation In Each Group

\begin{tabular}{|c|c|c|c|}
\hline & & & \\
\hline GP 1 & 1.70 & 0.21 & 20 \\
\hline GP 2 & 0.56 & 0.41 & 20 \\
\hline GP 3 & 0.87 & 0.1 & 20 \\
\hline GP4 & 1.43 & 0.12 & 20 \\
\hline
\end{tabular}

Table 3:-Following Table Represents The Comparison Of Mean Force Between All The Groups

\begin{tabular}{|l|r|r|r|l|}
\hline & & & & \\
\hline G1 Vs G2 & 1.14 & 0.54 & 9.3 & $<0.05$ \\
\hline G1 VsG3 & 0.82 & 0.23 & 15.54 & $<0.05$ \\
\hline G1 Vs G4 & 0.26 & 0.25 & 4.63 & $<0.05$ \\
\hline G2 Vs G3 & -0.31 & 0.42 & 3.33 & $<0.05$ \\
\hline G2 Vs G4 & -0.87 & 0.46 & 8.42 & $<0.05$ \\
\hline G3 Vs G2 & 0.32 & 0.42 & 3.33 & $<0.05$ \\
\hline G3 Vs G4 & -0.56 & 0.13 & 18.35 & $<0.05$ \\
\hline
\end{tabular}




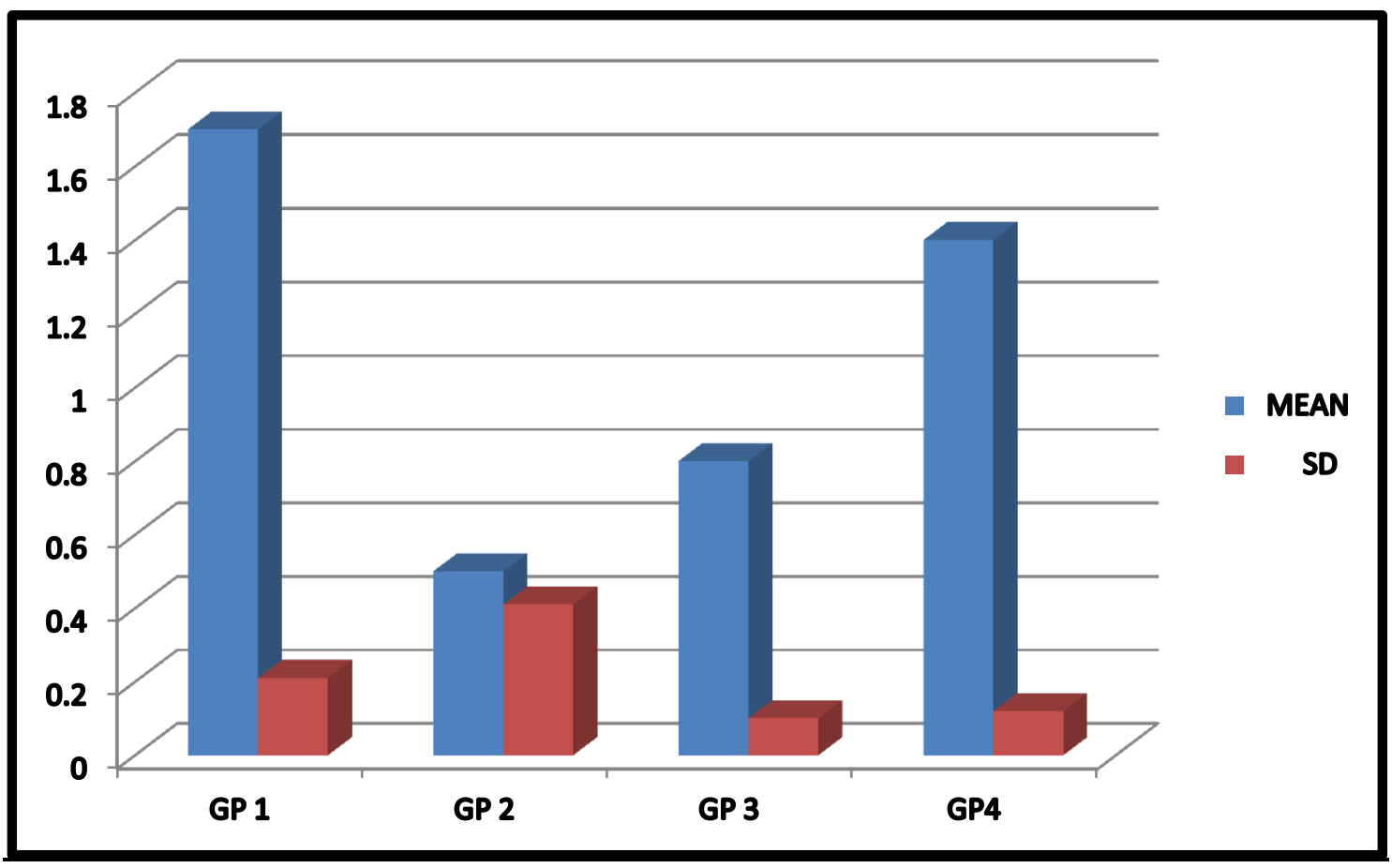

Graph 1:-Differences In Mean Force Required With Standard Deviaton In Each Group

\section{Bibliography:-}

1. Wilcox LR, Roskelley C, Sutton T. The relationship of root canal enlargement to finger spreader induced vertical root fracture. J Endod 1997;23:533-34.

2. Lertchirakarn V, Timyam A, Messer HH. Effects of root canal sealers on vertical root fracture resistance of endodontically treated teeth. J Endod 2002;28:217-19.

3. Oliveira FC,Deneny GE,Boyer DB. Fracture resistance of endodontically prepared teeth using various restorative materials. J Am Dent Assoc 1987;115:57-60.

4. El Nasr HM, El Kader KG. Dentinal damage and fracture resistance of oval roots prepared with single-file systems using different kinematics. J Endod 2014 Jun 30;40(6):849-51.

5. Yoldas O, Yilmaz S, Atkan G, Kudan C, Kasan Z. Dentinal microcrack formation during root canal preparations by different NiTi rotary instruments and the self-adjusting file.J Endod 2012 Feb;38(2):232-5.

6. Harvey TE, White JT, Leeb IJ. Lateral condensation stress in root canals .J Endod 1981;7:151-55.

7. Kumaran P,Sivapriya E,Indhramohan J,Gopikrishna V.Dentinal defects before and after rotary root canal instrumentation with three different obturation technique and two obturating materials J Cons Dent 2013;16:52226.

8. Capar ID, Altunsoy M, Arslan H, Ertas H, Aydinbelge HA. Fracture strength of roots instrumented with selfadjusting file and the ProTaper rotary systems. Journal of endodontics. 2014 Apr 30;40(4):551-4.

9. Lee JJ, Nettey-Marbell A, Cook A, Pimenta LA, Leonard R, Ritter AV. Using extracted teeth for research: the effect of storage medium and sterilization on dentin bond strengths. The Journal of the American Dental Association. 2007 Dec 31;138(12):1599-603.

10. Johnson WT, Noblett WC, Cleaning and shaping in: Endodontics; Principles and Practice. $4^{\text {th }}$ ed. Saunders, Philadelphia, PA,2009.

11. Blum JY, Parahy E, Micallef JP. Analysis of the forces developed during obturation: warm vertical compaction. J Endod. 1997 Feb;23(2):91-5.

12.Zhang W, Li Z, Peng B. Assessment of a new root canal sealer's apical sealing ability. Oral Surgery, Oral Medicine, Oral Pathology, Oral Radiology, and Endodontology. 2009 Jun 30;107(6):79-82.

13. Pişkin B, Aydın B, Sarıkanat M. The effect of spreader size on fracture resistance of maxillary incisor roots. International endodontic journal. 2008 Jan 1;41(1):54-9.

14. Topçuoğlu HS, Arslan H, Keleş A, Köseoğlu M. Fracture resistance of roots filled with three different obturation techniques. Med Oral Patol Oral Cir Bucal. 2012 May 1;17:e528-32. 
15. Shemesh $\mathrm{H}$, Wesselink $\mathrm{PR}, \mathrm{Wu} \mathrm{MK}$. Incidence of dentinal defects after root canal filling procedures. International endodontic journal. 2010 Nov 1;43(11):995-1000.

16. Shemesh H, Bier CA, Wu MK, Tanomaru-Filho M, Wesselink PR. The effects of canal preparation and filling on the incidence of dentinal defects. International Endodontic Journal. 2009 Mar 1;42(3):208-13.

17. Shaheen NA, Farag AM, Alhadainy HA, Darrag AM. Fracture resistance of endodontically treated roots using different preparation-obturation combinations. Tanta Dental Journal. 2013 Aug 31;10(2):97-102.

18. Metzger Z. The self-adjusting file (SAF) system: An evidence-based update. Journal of Conservative Dentistry. 2014 Sep 1;17(5):401.

19. Meister F, Lommel TJ, Gerstein H. Diagnosis and possible causes of vertical root fractures. Oral Surgery, Oral Medicine, Oral Pathology. 1980 Mar 1;49(3):243-53.

20.Liu R, Hou BX, Wesselink PR, Wu MK, Shemesh H. The incidence of root microcracks caused by 3 different single-file systems versus the ProTaper system. Journal of endodontics. 2013 Aug 31;39(8):1054-6.

21. Versiani MA, Pécora JD, de Sousa-Neto MD. Flat-oval root canal preparation with self-adjusting file instrument: a micro-computed tomography study. Journal of endodontics. 2011 Jul 31;37(7):1002-7.

22. Kaya S, Yiğit-Özer S, Adigüzel Ö. Evaluation of radicular dentin erosion and smear layer removal capacity of Self-Adjusting File using different concentrations of sodium hypochlorite as an initial irrigant. Oral Surgery, Oral Medicine, Oral Pathology, Oral Radiology, and Endodontology. 2011 Oct 31;112(4):524-30.

23. Karapinar Kazandag M, Sunay H, Tanalp J, Bayirli G. Fracture resistance of roots using different canal filling systems. International endodontic journal. 2009 Aug 1;42(8):705-10.

24. Sagsen B, Er O, Kahraman Y, Akdogan G. Resistance to fracture of roots filled with three different techniques. International endodontic journal. 2007 Jan 1;40(1):31-5.

25. Onnink PA, Davis RD, Wayman BE. An in vitro comparison of incomplete root fractures associated with three obturation techniques. Journal of Endodontics. 1994 Jan 31;20(1):32-7.

26. KISHEN A. Mechanisms and risk factors for fracture predilection in endodontically treated teeth. Endodontic topics. 2006 Mar 1;13(1):57-83.

27. Lertchirakarn V, Palamara JE, Messer HH. Load and strain during lateral condensation and vertical root fracture. Journal of endodontics. 1999 Feb 28;25(2):99-104.

28. Wu MK, Van Der Sluis LW, Wesselink PR. Comparison of mandibular premolars and canines with respect to their resistance to vertical root fracture. Journal of dentistry. 2004 May 31;32(4):265-8.

29. Dang DA, Walton RE. Vertical root fracture and root distortion: effect of spreader design. Journal of Endodontics. 1989 Jul 31;15(7):294-301.

30. Saw LH, Messer HH. Root strains associated with different obturation techniques. Journal of Endodontics. 1995 Jun 30;21(6):314-20.

31.Lindauer PA, Campbell AD, Hicks ML, Pelleu GB. Vertical root fractures in curved roots under simulated clinical conditions. Journal of endodontics. 1989 Aug 31;15(8):345-9.

32. Tamse A, Fuss Z, Lustig J, Kaplavi J. An evaluation of endodontically treated vertically fractured teeth. Journal of endodontics. 1999 Jul 31;25(7):506-8.

33. Wilcox LR, Roskelley C, Sutton T. The relationship of root canal enlargement to finger-spreader induced vertical root fracture. Journal of Endodontics. 1997 Aug 31;23(8):533-4.

34. Bouillaguet S, Shaw L, Barthelemy J, Krejci I, Wataha JC. Long-term sealing ability of pulp canal sealer, AHPlus, GuttaFlow and epiphany. International Endodontic Journal. 2008 Mar 1;41(3):219-26.

35. Vire DE. Failure of endodontically treated teeth: classification and evaluation. Journal of endodontics. 1991 Jul 31;17(7):338-42.

36. Pawar AM, Barfiwala D, Pawar M, Metzger Z, Kfir A, Jain N. Assessment of the fracture resistance of teeth instrumented using 2 rotary and 2 reciprocating files versus the Self-Adjusting File (SAF): An ex vivo comparative study on mandibular premolars. Journal of conservative dentistry: JCD. 2016 Mar;19(2):138.

37. Aydin U, Aksoy F, Karataslioglu E, Yildirim C. Effect of ethylenediaminetetraacetic acid gel on the incidence of dentinal cracks caused by three novel nickel-titanium systems. Australian Endodontic Journal. 2015 Dec 1;41(3):104-10.

38. Secilmis A, Dilber E, Ozturk N, Yilmaz FG. The Effect of Storage Solutions on Mineral Content of Enamel. Materials Sciences and Applications. 2013 Jun 28;4(07):439.

39. Pawar AM, Pawar SM, Pawar MG, Kokate SR. Fracture resistance of teeth instrumented by the Self-Adjusting File, ProTaper NEXT and WaveOne. Journal of Pierre Fauchard Academy (India Section). 2014 Sep 30;28(3):83-7.

40. Metzger Z, Kfir A, Abramovitz I, Weissman A, Solomonov M. The self-adjusting file system. ENDO (Lond Eng). 2013;7:189-210. 
41. Nagas E, Uyanik MO, Eymirli A, Cehreli ZC, Vallittu PK, Lassila LV, Durmaz V. Dentin moisture conditions affect the adhesion of root canal sealers. Journal of Endodontics. 2012 Feb 29;38(2):240-4.

42. Bhat SS, Hegde SK, Rao A, Mohammed AS. Evaluation of resistance of teeth subjected to fracture after endodontic treatment using different root canal sealers: an in vitro study. Journal of Indian Society of Pedodontics and Preventive Dentistry. 2012 Oct 1;30(4):305.

43. Uzunoglu E, Yilmaz Z, Erdogan O, Görduysus M. Final Irrigation Regimens Affect Fracture Resistance Values of Root-filled Teeth. Journal of endodontics. 2016 Mar 31;42(3):493-5. 